\title{
Assimilation of sea-ice concentration in a global climate model - physical and statistical aspects
}

\author{
S. Tietsche ${ }^{1,2, *}$, D. Notz ${ }^{1}$, J. H. Jungclaus ${ }^{1}$, and J. Marotzke ${ }^{1}$ \\ ${ }^{1}$ Max Planck Institute for Meteorology, Bundesstr. 53, 20146 Hamburg, Germany \\ ${ }^{2}$ International Max Planck Research School on Earth System Modelling, Hamburg, Germany \\ *now at: NCAS-Climate, University of Reading, Reading, UK
}

Correspondence to: S. Tietsche (s.tietsche@ reading.ac.uk)

Received: 30 June 2012 - Published in Ocean Sci. Discuss.: 19 July 2012

Revised: 20 November 2012 - Accepted: 4 December 2012 - Published: 15 January 2013

\begin{abstract}
We investigate the initialisation of Northern Hemisphere sea ice in the global climate model ECHAM5/MPI-OM by assimilating sea-ice concentration data. The analysis updates for concentration are given by Newtonian relaxation, and we discuss different ways of specifying the analysis updates for mean thickness. Because the conservation of mean ice thickness or actual ice thickness in the analysis updates leads to poor assimilation performance, we introduce a proportional dependence between concentration and mean thickness analysis updates. Assimilation with these proportional mean-thickness analysis updates leads to good assimilation performance for sea-ice concentration and thickness, both in identical-twin experiments and when assimilating sea-ice observations. The simulation of other Arctic surface fields in the coupled model is, however, not significantly improved by the assimilation. To understand the physical aspects of assimilation errors, we construct a simple prognostic model of the sea-ice thermodynamics, and analyse its response to the assimilation. We find that an adjustment of mean ice thickness in the analysis update is essential to arrive at plausible state estimates. To understand the statistical aspects of assimilation errors, we study the model background error covariance between ice concentration and ice thickness. We find that the spatial structure of covariances is best represented by the proportional mean-thickness analysis updates. Both physical and statistical evidence supports the experimental finding that assimilation with proportional mean-thickness updates outperforms the other two methods considered. The method described here is very simple to implement, and gives results that are sufficiently good to be used for initialising sea ice in a global climate model for seasonal to decadal predictions.
\end{abstract}

\section{Introduction}

For skillful seasonal to decadal predictions, good initial conditions of atmosphere-ocean global climate models (AOGCMs) are of paramount importance. So far, global prediction studies have been restricted to the initialisation of the oceanic and atmospheric state (e.g., Smith et al., 2007; Pohlmann et al., 2009). However, slow surface processes might constitute a substantial source of untapped predictability (Hurrell et al., 2009; Shepherd et al., 2011). One of the most important of these surface processes is arguably the existence of sea ice at high latitudes. Holland et al. (2010) and Blanchard-Wrigglesworth et al. (2011a) have shown that Arctic sea ice has inherent predictability of up to two years. Moreover, anomalies in Arctic sea ice can have an influence far beyond the Arctic by changing the large-scale atmospheric circulation (Honda et al., 2009; Budikova, 2009; Francis and Vavrus, 2012) and the oceanic thermohaline circulation (Koenigk et al., 2006; Levermann et al., 2007). Hence, the initialisation of sea ice in an AOGCM with suitable data assimilation techniques is an important step towards more skillful seasonal to decadal predictions. Here, we investigate data assimilation techniques for the initialisation of Northern Hemisphere sea ice in the AOGCM ECHAM5/MPI-OM.

For climate studies, the most important parameters of sea ice are the sea-ice concentration, which is the fraction of surface area covered by sea ice, and the sea-ice mean thickness, which is the volume of sea ice present per surface area. While the observational record of ice concentration in the Arctic is dense in space and time, and relatively reliable since the late 1970's, observations for ice thickness are sparse. Hence, 
sea-ice data assimilation suffers from a large uncertainty about the true thickness. Initial conditions derived from the assimilation inherit this uncertainty, which in turn severely limits the reliability of sea-ice predictions.

Previous studies have demonstrated that the assimilation of observed sea-ice concentration in ice-ocean models improves the simulated concentration (Lisæter et al., 2003; Lindsay and Zhang, 2006; Stark et al., 2008). However, the improvement in ice thickness is not straightforward, and Dulière and Fichefet (2007) emphasised that the assimilation can easily deteriorate the model performance if inappropriate assimilation techniques are chosen.

These findings from ice concentration assimilation in iceocean models forced by atmospheric surface conditions cannot be directly transferred to ice-concentration assimilation in AOGCMs, because in AOGCMs the atmospheric surface conditions are not necessarily consistent with the assimilated sea-ice state. Rather, they develop interactively from largescale dynamics and from local interaction with the sea-ice state. This makes the impact of ice-concentration assimilation on ice thickness less obvious than in ice-ocean models and calls for dedicated studies on sea-ice data assimilation in an AOGCM. To our knowledge, the only such published study is by Saha et al. (2010), who did not describe the impact of the ice concentration assimilation on ice thickness.

Here, we assimilate observations of Northern Hemisphere sea-ice concentration and compare different methods of prescribing changes in mean ice thickness associated with changes in ice concentration during the assimilation step. We systematically assess the assimilation performance both for concentration and thickness, and use conceptual arguments to explain the differences in assimilation performance.

The rest of the paper is organised as follows: Sect. 2 describes the global climate model used for this study, in particular the sea-ice component. Section 3 introduces the sea-ice data assimilation methods which we use to investigate feasibility of sea-ice data assimilation. The assimilation performance is evaluated first in identical-twin experiments (Sect. 4) and then with actual observations of sea-ice concentration (Sect. 5). Section 6.1 uses both a simple model and an AOGCM case study to develop a conceptual understanding of assimilation errors, while Sect. 6.2 analyses the model error statistics. Section 7 presents conclusions.

\section{The coupled global climate model}

\subsection{The atmosphere and ocean models}

Our AOGCM consists of the atmosphere component ECHAM5 (Roeckner et al., 2003) with a T31 horizontal resolution and 19 vertical levels, and the ocean component MPI-OM (Marsland et al., 2003) with a curvilinear grid that has a horizontal resolution of $50-200 \mathrm{~km}$ in the Arctic and 40 vertical levels. The time step of the atmosphere model is $40 \mathrm{~min}$, the time step of the ocean and sea-ice models is $144 \mathrm{~min}$. The ocean and atmosphere exchange surface fields once a day before the first time step. The model setup is a coarse-resolution version of the IPCC-AR4 model described by Jungclaus et al. (2006).

\subsection{The sea-ice model}

The sea-ice model in ECHAM5/MPI-OM is based on Hibler III (1979) and Semtner (1976). It consists of three prognostic equations for the mean ice thickness $h_{\mathrm{m}}(x, y, t)$, the ice concentration $C(x, y, t)$, and the ice velocity $\boldsymbol{v}(x, y, t)$ :

$\partial_{\mathrm{t}} h_{\mathrm{m}}=\nabla \cdot\left(h_{\mathrm{m}} \boldsymbol{v}\right)+S_{h}$

$\partial_{\mathrm{t}} C=\nabla \cdot(C \boldsymbol{v})+S_{C}$

$\partial_{\mathrm{t}} \boldsymbol{v}=-f(\boldsymbol{k} \times \boldsymbol{v})-g \nabla \zeta+\frac{\boldsymbol{\tau}_{\mathrm{a}}}{\rho_{\mathrm{i}} h_{\mathrm{m}}}+\frac{\boldsymbol{\tau}_{\mathrm{o}}}{\rho_{\mathrm{i}} h_{\mathrm{m}}}+\nabla \cdot \boldsymbol{\sigma}$.

The divergence terms on the right-hand side of Eqs. (1) and (2) describe the redistribution of ice volume and concentration by advection with ice velocity $v . S_{h}$ and $S_{C}$ are the thermodynamic sources of mean thickness and concentration, respectively, which describe local melting and freezing. The change of ice velocity $\boldsymbol{v}=\left(v_{\mathrm{x}}, v_{\mathrm{y}}\right)$ is determined by the momentum balance of Eq. (3), where $f$ is the Coriolis parameter, $\boldsymbol{k}$ the vertical unit vector, $g$ the Earth's gravitational acceleration, $\zeta$ the sea-surface height above sea-level, $\rho_{\mathrm{i}}$ the ice density, $\boldsymbol{\tau}_{\mathrm{a} / \mathrm{o}}$ the stress of wind from above and of ocean current from below, and $\sigma$ the sea-ice internal stress tensor. The terms on the right-hand side of Eq. (3) from left to right correspond to forces that originate in the Coriolis effect, the tilt of the sea-surface, the drag from atmosphere and ocean, and internal sea-ice stresses.

These equations are based on the model assumption that within a grid cell, a fraction $C$ of the area is covered by thick ice with the constant actual thickness $h_{\mathrm{t}}$, and the remaining fraction $1-C$ of the area is open water. The actual thickness $h_{\mathrm{t}}$ is connected to the mean ice thickness $h_{\mathrm{m}}$ by

$h_{\mathrm{m}}=C h_{\mathrm{t}}$.

It is further assumed that the sea-water in a grid cell that contains sea ice is always at a representative sea-water freezing temperature of $-1.9^{\circ} \mathrm{C}$. Thus, any heat flux imbalance over either the ice-covered or the open-water part of the grid cell is immediately converted into ice growth or melt, and so the thermodynamic source of mean ice thickness in Eq. (1) is given by:

$S_{h}=C g_{\mathrm{i}}+(1-C) g_{\mathrm{w}}$.

The two different growth rates, $g_{\mathrm{i}}$ for the ice-covered part of the grid cell and $g_{\mathrm{w}}$ for the open-water part, are calculated 
from the surface energy balance of the coupled model, assuming a linear temperature profile within the ice (Semtner, 1976).

The thermodynamic source term for ice concentration $S_{C}$ is parametrised in terms of the ice growth rates according to Hibler III (1979):

$S_{C}=\Theta\left(g_{\mathrm{w}}\right) \frac{g_{\mathrm{w}}}{h_{0}}(1-C)+\Theta\left(-S_{h}\right) \frac{C}{2 h_{\mathrm{m}}} S_{h}$,

with $\Theta$ the Heaviside step function (i.e. $\Theta(x)=1$ if $x \geq 0$, $\Theta(x)=0$ if $x<0)$. The first term on the right-hand side of Eq. (6) is active when new ice forms from open water; the parameter $h_{0}=0.5 \mathrm{~m}$ is chosen such that open water freezes over within a few days if there is strong ice growth. The second term approximates the decrease in ice concentration when thick ice melts, assuming that the thickness of the ice floe is distributed linearly between 0 and $2 h_{\mathrm{t}}$. A critical discussion of Eq. (6) is provided by Mellor and Kantha (1989).

\section{Sea-ice data assimilation approach}

In this study, we utilise daily data of Arctic sea-ice concentration. In Sect. 4, these data are derived from model output, whereas in Sect. 5 they are derived from satellite observations. For the concentration analysis updates, we choose here the simplest possible approach: the Newtonian relaxation of the model state towards observations (Lindsay and Zhang, 2006). This approach is feasible here since sea-ice concentration observations are both dense and relatively reliable. The analysis updates of other sea ice-related variables like mean ice thickness, sea-surface temperature and sea-surface salinity are derived from the concentration analysis updates as described in Sects. 3.2 and 3.3.

We remind the reader that Newtonian relaxation is the simplest conceivable data assimilation scheme. It does not account for spatial correlation in model and observations; nor does it account for multivariate covariances, unless they are explicitly prescribed. Therefore, the state estimates obtained by this simple method should always be critically evaluated. For an overview of state-of-the-art data assimilation techniques, which in general provide far more consistent state estimates, see for instance Kalnay (2003). Nevertheless, there is one major advantage of the Newtonian Relaxation: its implementational complexity and computational costs are orders of magnitude smaller than those of more complex methods. If this simple approach delivers a state estimate that is good enough for the application at hand, we argue that it can be a very useful alternative to full-fledged assimilation methods. In our case, the application is the initialisation of sea ice in a global climate model for seasonal to decadal climate predictions. There, the usefulness of the initialisation can be easily inferred from the change in predictive skill that it provides.
We perform long assimilation runs for the period 1979-2007, spanning almost the entire satellite observational record of Northern Hemisphere sea-ice concentration. We primarily consider the global performance of sea-ice data assimilation, averaged over different regions and different years, rather than focus on specific case studies. On the one hand, this complicates the attribution of failure or success of a method to physical causes, since we deal with the average over a plethora of different local conditions. On the other hand, we can verify that there are no spurious drifts in the AOGCM induced by the sea-ice data assimilation and that the performance is robust over a range of climatic conditions.

In the following, we use the notation of Bouttier and Courtier (1999). For any variable $x$, we denote the model background state by $x^{\mathrm{b}}$ and the observed state by $x^{\mathrm{o}}$. Every time an assimilation step is performed, the departure of the modelled state $x^{\mathrm{b}}$ from the observed state $x^{\mathrm{o}}$ is calculated, and a correction $\Delta x$ is computed that depends on this departure. The correction $\Delta x$ is called the analysis update, and the corrected state $x^{\mathrm{a}}=x^{\mathrm{b}}+\Delta x$ is called the analysis.

\subsection{Analysis updates of ice concentration}

We obtain the analysed sea-ice concentration $C^{\mathrm{a}}$ once a day by correcting the model background concentration $C^{\mathrm{b}}$ with an analysis update $\Delta C$ that corresponds to Newtonian relaxation towards observed values $C^{\mathrm{o}}$ :

$C^{\mathrm{a}}=C^{\mathrm{b}}+\Delta C$ with $\Delta C=K_{\mathrm{N}}\left(C^{\mathrm{o}}-C^{\mathrm{b}}\right)$.

The scalar constant $K_{\mathrm{N}}$ determines the strength of the analysis update. This approach is akin to data assimilation by nudging, where the same analysis update would be applied at each time step of the model. For all our experiments, we choose $K_{\mathrm{N}}=0.1$. Without model interaction, the analysis update in Eq. (7) with $K_{\mathrm{N}}=0.1$ applied once a day leads to the exponential relaxation of an initial departure of the model background state from the observation on a relaxation time scale of $T_{R}=10$ days. Thus, the time scale of the assimilation matches the time scale on which large-scale changes in sea ice can occur. Section 6.2 discusses further implications of the choice of $K_{\mathrm{N}}$.

\subsection{Analysis updates of mean ice thickness}

We consider analysis updates of mean ice thickness $h_{\mathrm{m}}$ as a function of analysis updates of ice concentration:

$h_{\mathrm{m}}^{\mathrm{a}}=h_{\mathrm{m}}^{\mathrm{b}}+\Delta h_{\mathrm{m}}$ with $\Delta h_{\mathrm{m}}=f(\Delta C)$.

Our motivation to follow this approach is twofold: (i) reliable and dense satellite observations of mean ice thickness are not available to date, and (ii) anomalies in ice concentration and mean ice thickness are correlated (Lisæter et al., 2003; Zhang, 2010). By choosing $f$ so that it approximates these correlations, we can try to estimate the mean thickness from observation of sea-ice concentration alone. 
It is to be expected that this approach works well close to the ice edge, where concentration is very variable, and correlation between concentration and thickness is strong. In the central Arctic, however, ice concentration is almost always close to $100 \%$, and the correlation between concentration and thickness is weak. There, we cannot expect this approach to correct ice thickness from concentration data effectively.

As we will see in Sects. 4 and 5, the assimilation error differs substantially between different choices for the functional dependence $f$, and in Sects. 6.1 and 6.2 we will discuss possible sources of assimilation errors in detail. We introduce and discuss the following three choices:

\subsubsection{Analysis updates with conserved mean thickness (CMT)}

With this method, the analysis update of mean ice thickness $h_{\mathrm{m}}$ is always zero, no matter the value of the concentration analysis update:

$\Delta h_{\mathrm{m}}=0$.

The analysed actual ice thickness $h_{\mathrm{t}}^{\mathrm{a}}$ is then given by $h_{\mathrm{t}}^{\mathrm{a}}=$ $h_{\mathrm{t}}^{\mathrm{b}} C^{\mathrm{b}} / C^{\mathrm{a}}$. From idealised experiments with prescribed perturbations in thermodynamic atmospheric forcing, Dulière and Fichefet (2007) concluded that this is the best approach when model error is mainly due to ice advection.

\subsubsection{Analysis updates with conserved actual thickness (CAT)}

We assume that the model has the correct actual ice thickness $h_{\mathrm{t}}$, and demand that $\Delta h_{\mathrm{t}} \equiv h_{\mathrm{t}}^{\mathrm{a}}-h_{\mathrm{t}}^{\mathrm{b}} \stackrel{!}{=} 0$. Applying Eqs. (4) and (8), we see that this is guaranteed if we choose:

$\Delta h_{\mathrm{m}}=h_{\mathrm{t}}^{\mathrm{b}} \Delta C$,

where $h_{\mathrm{t}}^{\mathrm{b}}=h_{\mathrm{t}}^{\mathrm{b}}(x, y, t)$ is the spatially and temporally varying actual thickness in the model background. Thus, for the same concentration analysis update, mean-thickness analysis updates will be small for low background actual thickness, and large for high background actual thickness. Dulière and Fichefet (2007) found that this method performs best when model error is mainly due to ice thermodynamics.

\subsubsection{Proportional mean thickness analysis updates (PMT)}

Dulière and Fichefet (2007) report best assimilation results for a combination of CMT and CAT, depending on whether errors are related to errors in the thermodynamic or the dynamic forcing of the sea ice. However, in an AOGCM the attribution of errors in the sea-ice state to either dynamical or thermodynamical processes is not practicable. Hence, we propose a simple new scheme that - as we will show - performs well independent of the source of the errors. This is a scheme where the mean-thickness analysis updates have a fixed proportionality to the concentration analysis updates:

$\Delta h_{\mathrm{m}}=h^{*} \Delta C$.

The proportionality constant $h^{*}$ is a free parameter. In our experiments, we use a value of $h^{*}=2 \mathrm{~m}$. That means that for a concentration update of $1 \%$ we change the mean ice thickness by $2 \mathrm{~cm}$. However, we find that the assimilation performance considered in Sects. 4 and 5 is not very sensitive to changing $h^{*}$ in the range $0.5 \mathrm{~m} \leq h^{*} \leq 4 \mathrm{~m}$. Our choice of $h^{*}$ is supported by the frequency of occurrence of mean thickness and concentration in the AOGCM (see Sect. 6.1) and the model background error covariance between concentration and thickness diagnosed from the AOGCM (Sect. 6.2).

\subsection{Analysis updates of sea-surface temperature and salinity}

Growth and melt of sea ice are strongly coupled to the properties of the sea-water directly below and adjacent to the ice. Thus, sea-ice data assimilation schemes for a model with a prognostic ocean need to find a satisfying solution to adjust sea-surface salinity (SSS) and sea-surface temperature (SST) when changing the sea-ice state through the analysis updates.

In ECHAM5/MPI-OM, the assimilation of SST in the presence of sea ice is implicitly provided by the assumption of thermodynamic equilibrium between sea ice and the water in the ocean surface layer. If sea ice is present in the observations, but not in the model, positive analysis updates of ice concentration merely lead to a decrease in SST until the freezing point is reached. In this case, analysis updates for sea ice are effectively zero, while we have negative analysis updates of SST. As soon as ice starts to form, SST stays constant at the freezing temperature, and the analysis updates change only the sea-ice concentration and thickness.

The SSS plays an important role for the establishment or inhibition of oceanic convection in the presence of sea ice. If there is convection, the entrainment of warm water from below during the deepening of the surface mixed layer can inhibit ice growth considerably (see, for instance, Lemke, 1987). Since growth and melt of sea ice provide substantial freshwater fluxes into the ocean surface water, the treatment of SSS in the analysis update will strongly interact with the sea-ice analysis. The character of this interaction, however, is very variable and depends on the specific local conditions. Since the covariance between ice concentration and SSS shows such a high degree of complexity (Lisæter et al., 2003), it is not feasible to prescribe a global time-independent functional relation between the analysis updates that exploits the existing covariance structures.

In our experiments, we assume that no knowledge about appropriate SSS analysis updates can be derived from the analysis updates of sea-ice concentration, and therefore we do not change SSS in the assimilation step. 


\section{Assimilating sea-ice data in identical-twin experiments}

\subsection{Rationale and method}

When assimilating observed sea-ice concentration in an AOGCM, we face two basic problems: (i) the ice thickness and the state of the ocean below sea ice are poorly observed, hence we cannot determine if the assimilation improves those variables, and (ii) we cannot decide if problems in the assimilation are due to drawbacks in the assimilation scheme or due to model biases.

Those issues can be addressed in a so-called "identicaltwin" or "perfect-model" study. In the data assimilation context, this means that we treat model output from a reference run as observations, and assimilate it back into a different run of the same model. When both model runs start from different but climatologically equivalent initial conditions and are exposed to the same external forcing, the model is perfect with respect to the reference-run observations. This allows us to disentangle the effects of model bias and data assimilation method and to answer the question, "If the model were perfect, would we be able to initialise it successfully with a given data assimilation approach?".

The reference run $R$ is started from a long control run with preindustrial conditions, and is then exposed to the observed greenhouse-gas forcing from 1900 onwards. In the reference run, the overall decrease of Northern Hemisphere sea-ice extent is comparable to observations, although the retreat of summer-time sea ice is somewhat underestimated. A detailed description of the deficiencies of the IPCC-AR4 version of this model in simulating Northern Hemisphere sea ice is given by Koldunov et al. (2010).

We obtain an equivalent but different realisation of natural climate variability by starting a second run $P$ in 1979 with exactly the same model setup, but from slightly perturbed initial conditions. The applied perturbation is a time shift of the model state by one day, and is hence comparatively small. However, the perturbation is quickly amplified by chaotic processes, so that important large-scale modes of climate variability, like ENSO, the slow components of the Atlantic meridional overturning circulation, and interannual variations in sea-ice cover are out of phase between the two runs.

The assimilation run $A$ starts from the same initial conditions as the perturbed run $P$, but assimilates the ice concentration from the reference run $R$. The time period considered is 1979 to 2007 , so that we can later compare the assimilation of ice concentration from model output to the assimilation of ice concentration from satellite observations.

To quantify the usefulness of the data assimilation, we measure the mismatch of a climate variable $X$ between any two time series with the root mean square differences between the two time series: $\delta X_{T_{1} T_{2}}=\sqrt{\left\langle\left(X_{T_{1}}(t)-X_{T_{2}}(t)\right)^{2}\right\rangle}$.

The expectation value $\langle\cdot\rangle$ is meant to be taken over time for aggregated quantities like Northern Hemisphere sea-ice extent, and over time and space for field variables like sea-ice concentration.

Using Eq. (12), we can compare the natural variability $\delta X_{\mathrm{RP}}$ with the assimilation error $\delta X_{\mathrm{RA}}$. Only if $\delta X_{\mathrm{RA}}<$ $\delta X_{\mathrm{RP}}$ does the assimilation actually improve the initialisation of $X$ in the model. For a perfect initialisation of $X$, we would have $\delta X_{\mathrm{RA}}=0$.

\subsection{Results}

For seasonal to decadal predictions of sea ice, the total ice volume and the total area covered are arguably the most important parameters (Holland et al., 2010; BlanchardWrigglesworth et al., 2011b). They are closely related to local ice thickness and ice concentration: ice volume is proportional to the sum of the mean thickness for all grid cells, and ice extent is the area sum of all grid cells with ice concentration higher than $15 \%$. In the following, we will therefore quantify the improvement brought by the data assimilation by discussing errors in ice volume and ice extent alongside root mean square errors (RMSE) of concentration and thickness.

Figure 1 shows how successfully the different assimilation schemes allow the assimilation run $A$ to match the annual mean sea-ice extent and sea-ice volume of the reference run $R$. The reference run has generally decreasing sea-ice extent and sea-ice volume in response to the warming background climate. Additionally, there are year-to-year variations as well as decadal-scale variations in the sea-ice state. For instance, between 1988 and 1991 sea-ice extent increases, stays relatively high until 1998, and then drops sharply to the lowest value of the time series in 2000 . We consider a sea-ice data assimilation successful only if (i) $A$ has the same climatology as $R$, i.e. the multi-year running means are the same, (ii) $A$ shows similar decadal-scale anomalies as $R$, and (iii) $A$ has year-to-year changes comparable to $R$.

The CMT assimilation scheme fails in all three criteria: it does not reproduce the negative trend in sea-ice volume, the period between 1984 and 1992 that should see a negative anomaly in sea-ice volume actually has a positive anomaly, and the small year-to-year fluctuations are not captured at all. The CAT run has a negative bias, but reasonably captures year-to-year and decadal variations. Finally, the PMT run meets all three criteria set above, and by far provides the best assimilation performance.

Table 1 shows the time-averaged error in annual mean sea-ice extent $\delta$ SIE and sea-ice volume $\delta$ SIV as defined in Eq. (12). Although all assimilation methods decrease the error in sea-ice extent with respect to the reference run, we see 

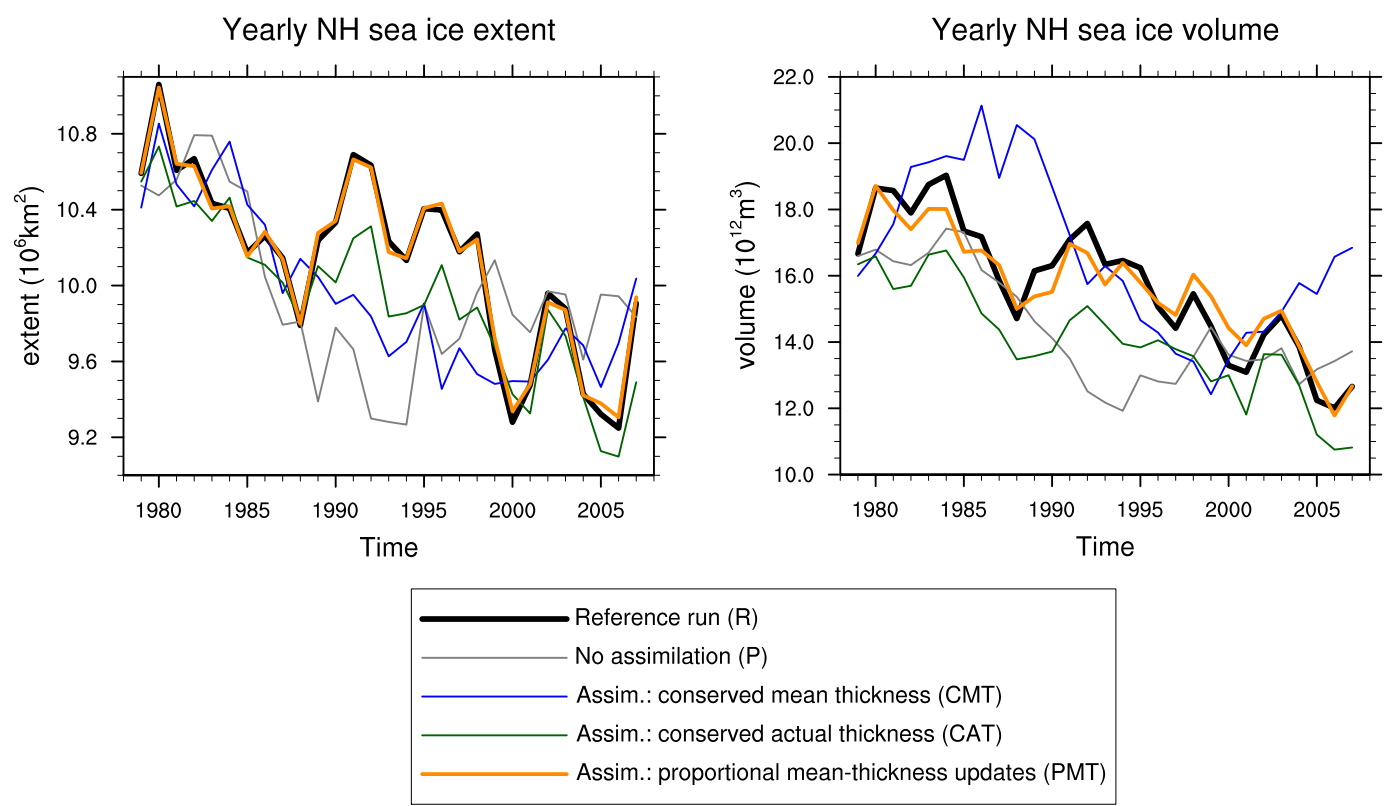

Fig. 1. Annual mean sea-ice extent (left) and sea-ice volume (right) in the Northern Hemisphere for the identical-twin study. Shown are the reference run (black), the perturbed run with no assimilation (grey), and the assimilation runs (colours) that assimilate sea-ice concentration from the reference run. The corresponding time-averaged global extent and volume errors $\delta$ SIE and $\delta$ SIV are given in Table 1 .

Table 1. Average assimilation error after Eq. (12) for annual mean Arctic ice volume and extent in the twin study (first and second column; cp. Fig. 1) and for annual mean Arctic ice extent when compared to observations (third column; cp. Fig. 3).

\begin{tabular}{l|cc|c}
\hline & \multicolumn{2}{|c|}{ Twin study } & Observations \\
& $\delta \operatorname{SIV}\left(10^{12} \mathrm{~m}^{3}\right)$ & $\delta \operatorname{SIE}\left(10^{12} \mathrm{~m}^{2}\right)$ & $\delta \operatorname{SIE~}\left(10^{12} \mathrm{~m}^{2}\right)$ \\
\hline No assimilation & 2.1 & 0.56 & 0.35 \\
CMT assimilation & 2.4 & 0.41 & 0.60 \\
CAT assimilation & 1.8 & 0.25 & 0.51 \\
PMT assimilation & 0.6 & 0.03 & 0.07 \\
\hline
\end{tabular}

that only PMT reduces the error in sea-ice volume far below the level of natural variability.

To analyse the seasonal cycle of the assimilation errors, we calculate the discrepancy in concentration $\delta C$ and mean thickness $\delta h_{\mathrm{m}}$ for the Arctic Ocean with Eq. (12), taking the time mean separately for each month of the year (Fig. 2a and b). Since the Arctic Ocean is essentially ice-covered during winter, even the no-assimilation run exhibits only small natural variations in sea-ice concentration, with $\delta C_{\mathrm{RP}} \approx 5-8 \%$. The summer melt, however, is much more variable, and concentration variability in the no-assimilation run reaches $24 \%$ in September and October. Clearly, all assimilation methods are able to significantly reduce the concentration discrepancy $\delta C$, although there are marked differences between the methods. The CMT gives the worst performance, and the PMT gives the best performance, reducing concentration error to about $5 \%$ year-round.
The error in mean thickness $\delta h_{\mathrm{m}}$ is shown in Fig. 2b. The natural variability $\delta h_{\mathrm{m}}(R, P)$ is about $40 \mathrm{~cm}$ in winter and about $50 \mathrm{~cm}$ in summer. It is evident that the CMT does not decrease, but even increases the error of mean ice thickness, i.e. $\delta h_{\mathrm{m}}(R, P)<\delta h_{\mathrm{m}}(R, A)$. This is quite a dramatic failure of the data assimilation method. In Sects. 6.1 and 6.2 we will see that there are good conceptual arguments why the CMT is not a suitable assimilation method in an AOGCM.

The two other methods (CAT and PMT) successfully reduce the thickness error. Again, PMT has the lowest thickness error; it is about $25-30 \mathrm{~cm}$ year-round. Note that the assimilation is most successful in summer, as it halves the error in the mean ice thickness compared to the natural variability.

We shall also assess the impact of the sea-ice data assimilation on Arctic climate variables that are closely related to sea ice, but not directly changed by the assimilation procedure: the Arctic Ocean SST and SSS, the Arctic Ocean mixed-layer depth, and the Arctic surface air temperature (SAT). In our simple assimilation method, these fields are constrained neither by observations nor by statistical relationships with analysis updates of sea-ice concentration, and so it is important to check whether our assimilation method introduces unexpected anomalies in these fields.

The error in Arctic Ocean SST (Fig. 2c) resembles the error in sea-ice concentration. Without assimilation, it is about $0.3 \mathrm{~K}$ in winter and about $1 \mathrm{~K}$ in summer. All assimilation methods reduce this error. The PMT method performs best and halves the SST error throughout the year. For the Arctic Ocean SSS field, all assimilation methods lead only to a small reduction of the error of 0 to $0.1 \mathrm{~g} \mathrm{~kg}^{-1}$ starting from 

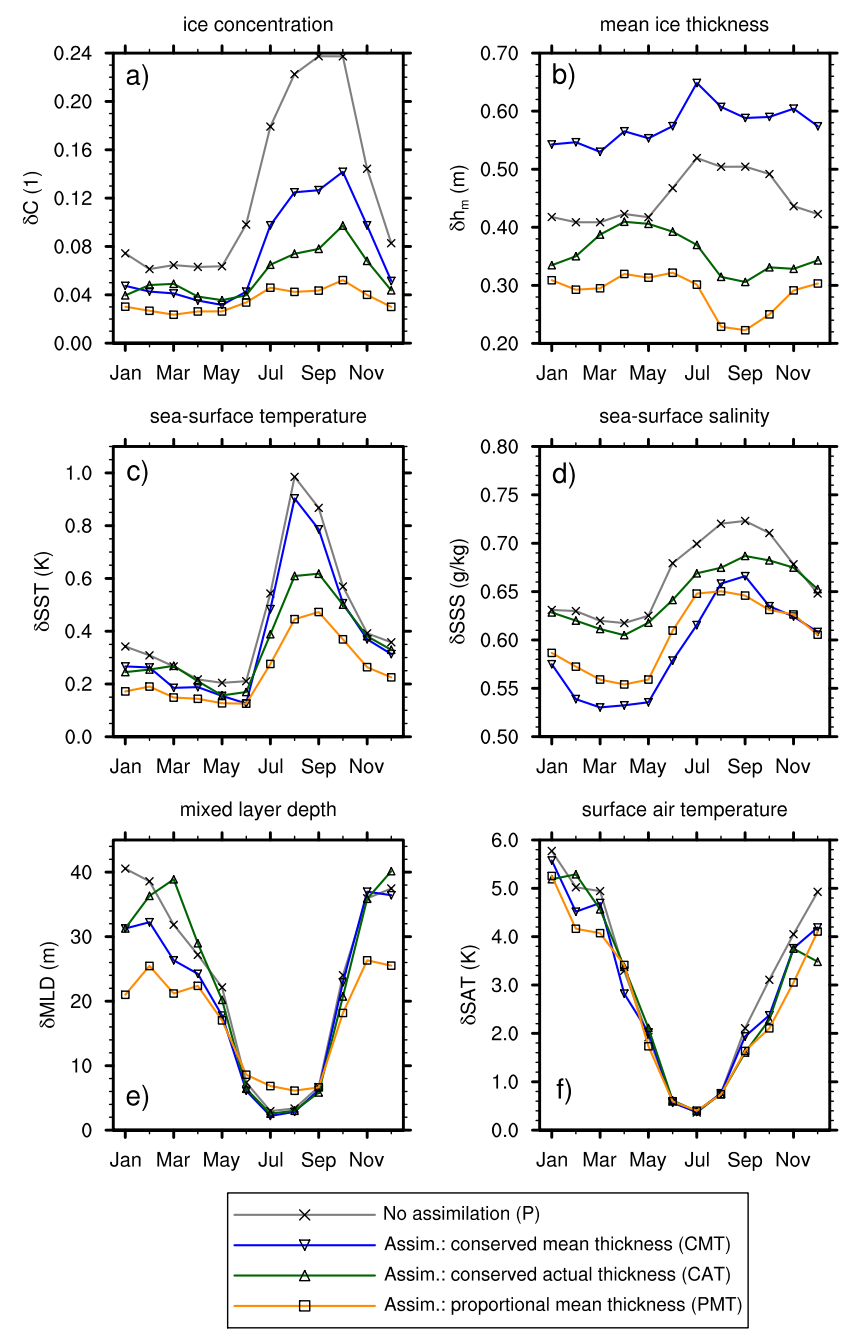

Fig. 2. Average point-wise root mean square error for each month over the Arctic Ocean for (a) sea-ice concentration, (b) sea-ice mean thickness (c) sea-surface temperature, (d) sea-surface salinity, (e) ocean mixed layer depth, and (f) surface air temperature. All errors are obtained from the differences to the reference run of the identical-twin experiments.

0.6 to $0.7 \mathrm{~g} \mathrm{~kg}^{-1}$ as the level of natural variability (Fig. 2d). This demonstrates that assimilation of sea-ice concentration with our approach is not very successful in constraining other variables in the climate model. The Arctic Ocean mixedlayer depth (Fig. 2e) shows even less positive impact of the assimilation. While assimilation with the PMT method reduces mixed-layer-depth error over the winter months, it increases the error over the summer months. Finally, for Arctic SAT we find a slight improvement caused by the assimilation between September and March, but little effect in summer months (Fig. 2f). In summary, we note that (i) the assimilation improves the considered non-sea-ice fields only marginally, but does not introduce unexpected anomalies in these fields, and (ii) the PMT assimilation performs better than the CMT and CAT methods also for the non-sea-ice fields considered.

\section{Assimilating sea-ice observations}

We now investigate how successfully we can assimilate satellite observations of sea-ice concentration into the coupled climate model. The observations are derived from Nimbus-7 SMMR and DMSP SSM/I passive microwave data, processed by the NSIDC with the NASA team algorithm (Cavalieri et al., 2008). Temporal resolution of the data is every two days, which we interpolate to daily values. The horizontal resolution is $25 \mathrm{~km}$, which we interpolate to the model resolution of about $50-200 \mathrm{~km}$. For an estimate of uncertainty in the sea-ice concentration observations, the reader may refer to Tonboe and Nielsen (2010), who arrive at an error estimate of around $10 \%$ on average. The assimilation methods we employ in this section are exactly the same as in the identical-twin study. We will again show ice extent alongside with concentration RMSE as a performance metric. Note that the observational uncertainties in year-to-year changes in ice extent are only in the order of $10^{4} \mathrm{~km}^{2}$ (NSIDC user service, personal communication), and are therefore negligible when discussing observed year-to-year changes in the order of $10^{6} \mathrm{~km}^{2}$.

\subsection{Ice concentration}

From Fig. 3 we see that the annual mean state of ice extent in ECHAM5/MPI-OM without data assimilation is reasonably close to the observed state. Of course, there are marked differences between the free model and the observations that are caused by natural variability - for instance, at the observed extreme extent minimum in 2007 the model actually has a temporary extent maximum.

Comparing Fig. 3 with Fig. 1, we see that the conclusions regarding the performance of the different methods are the same as in the identical-twin study: CMT fails as a sea-ice data assimilation approach in all quality criteria, CAT reproduces natural variability somewhat, but has a biased mean state, and PMT has both an acceptable mean state and reproduces natural variability satisfyingly. Considering the timeaveraged measure for the assimilation error in sea-ice extent, $\delta$ SIE, we see that only PMT is able to reduce $\delta$ SIE below the no-assimilation case (see Table 1).

The seasonal cycle of sea-ice concentration error in the Arctic (Fig. 4) also resembles the result from the identicaltwin study (Fig. 2a). Note, however, that during summer the free model state now exhibits larger errors of up to $30 \%$. Also, the errors for CMT and CAT are twice as large as in the identical-twin study, while the PMT shows only a slight increase in $\delta$ SIE compared to the identical-twin experiments.

In summary, we find that assimilating observations in ECHAM5/MPI-OM gives results for ice-extent and 


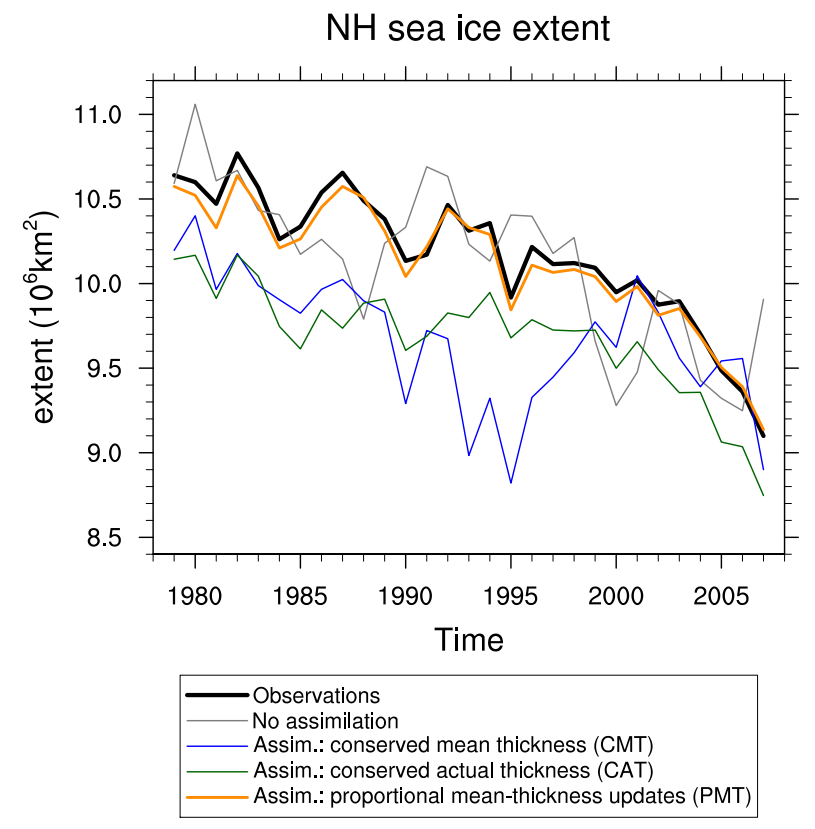

Fig. 3. Annual mean ice extent in the Northern Hemisphere from observations (black), a model run with no assimilation (grey), and from the different assimilation methods (colours). The corresponding time-averaged global extent errors $\delta$ SIE are given in Table 1.

ice-concentration error that are very similar to the results of assimilating output of the same model. This indicates that the assimilation performance for sea-ice concentration is determined more by deficiencies in the assimilation techniques rather than by model biases.

\subsection{Ice thickness}

There are currently only few large-scale ice thickness measurements available (Rothrock and Wensnahan, 2007; Kwok et al., 2009). For a direct comparison of the simulated ice thickness with observations, we need validated observations that cover the whole Arctic Ocean. The only such data set available to us are ice thickness measurements from the ICESat laser altimeter between 2005 and 2008 processed by $\mathrm{Yi}$ and Zwally (2010). These data have complete coverage of mean sea-ice thickness data north of $65^{\circ} \mathrm{N}$. Unfortunately, they are only available for a few discontinuous months, when the laser altimeter on the satellite was in operation. Due to the limited temporal coverage of direct observations, we also compare our assimilation results to the PIOMAS reanalysis of Arctic sea-ice volume, which has been thoroughly validated against all available observations of ice thickness (Schweiger et al., 2011).

As shown in Fig. 5, there are differences between the ICESat and PIOMAS ice volume estimates of up to $3000 \mathrm{~km}^{3}$, which are, however, mostly compatible with their respective uncertainties as estimated by Kwok et al. (2009) and Schweiger et al. (2011). The relative anomaly of the annual

\section{Arctic Ocean concentration error}

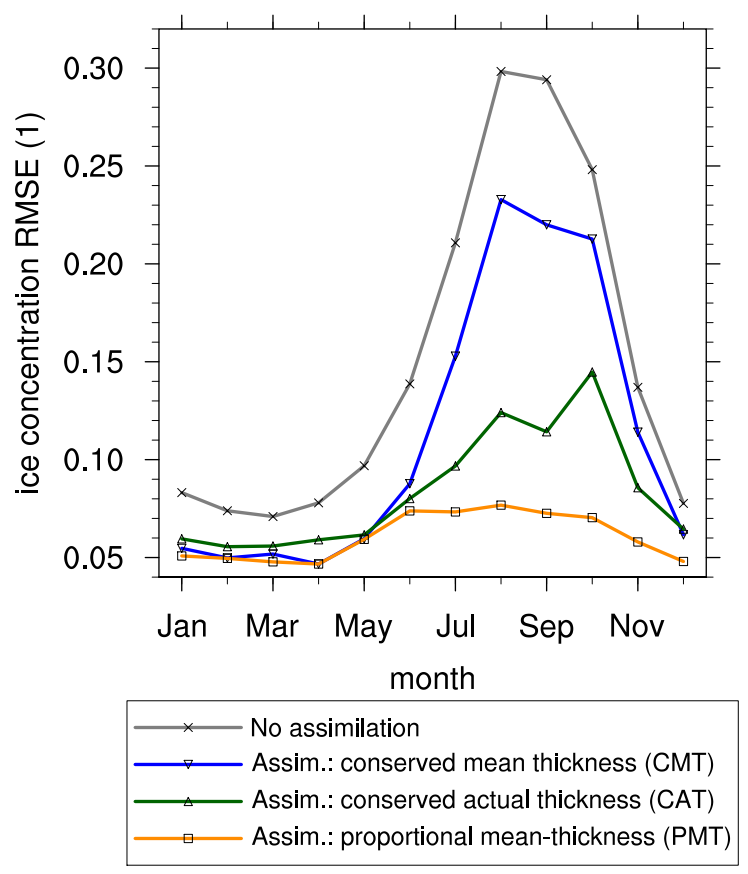

Fig. 4. The average point-wise error in sea-ice concentration for the Arctic Ocean for each month of the year. All errors are obtained from the differences to the observed concentration fields.

sea-ice minimum in 2007 with respect to the previous years is a prominent feature in both data sets.

The no-assimilation run with ECHAM5/MPI-OM has too low an ice volume throughout. All assimilation methods bring the ice volume closer to both ICESat and PIOMAS estimates. Nevertheless, the CMT assimilation run performs less well regarding two aspects: first, it consistently overestimates the seasonal cycle in comparison with PIOMAS; and second, it does not show anomalously low volume in 2007 with respect to the previous years. The CAT and PMT methods on the other hand are always - except for ICESat data in March 2007 - within the error bars of both PIOMAS and ICESat volume estimates, and they do capture the 2007 anomaly.

\section{Understanding assimilation errors}

\subsection{Physical aspects - local sea-ice growth rates}

We have seen in Sect. 4.2 that assimilating sea-ice data in an AOGCM does not necessarily lead to an improvement of the simulated sea-ice state. In particular, the assimilation of ice concentration can deteriorate the representation of ice thickness. We now show that this can largely be explained by considering the local sea-ice energy balance.

Local sea-ice growth rates depend heavily on concentration, as detailed in Appendix A. This has implications for 


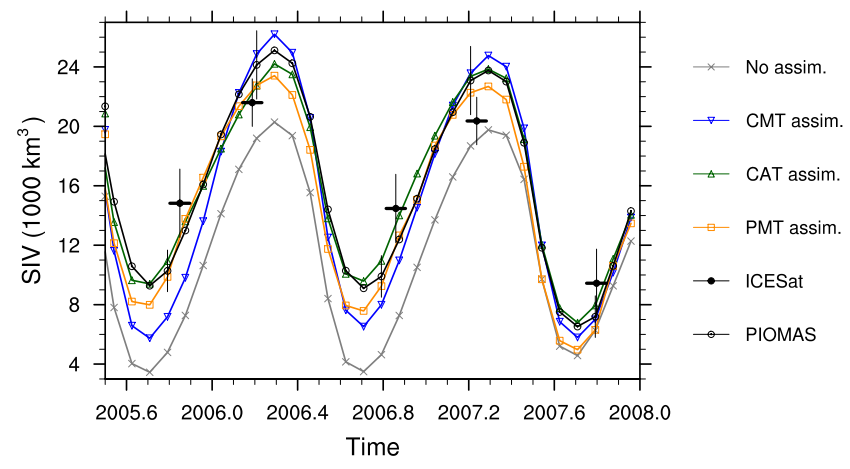

Fig. 5. Monthly mean of Arctic sea-ice volume between 2005 and 2008, as modelled with MPIOM-ECHAM5 and estimated from ICESat observations and the PIOMAS reanalysis. Thin vertical lines give uncertainties in ICESat and PIOMAS estimates as given by Kwok et al. (2009) and Schweiger et al. (2011).

the development of mean ice thickness when assimilating ice concentration: in summer, the melt rate decreases with increasing concentration. Therefore, assimilating high ice concentration without any thickness correction leads to less melt and thicker ice than without the assimilation. In winter, the atmospherically driven growth rate decreases with increasing concentration. Therefore, assimilating low ice concentration leads to enhanced growth and thicker ice. While this thickness response leads to plausible ice states during summer, it leads to an inconsistent combination of low concentration and high mean thickness during winter.

To quantify this effect and to illustrate the difference between the CMT and PMT assimilation techniques, we apply the assimilation to a local ice-energy balance model (IEBM) derived from the sea-ice model Eqs. (1) and (2) and driven by atmospheric downwelling radiation. As shown in Appendix A1, these IEBM equations, combined with a continuous version of the relaxation terms discussed in Sect. 3, can be written as

$$
\begin{aligned}
\frac{\mathrm{d} C}{\mathrm{~d} t} & =S_{C}+N_{C}=\Theta\left(g_{\mathrm{w}}\right) \frac{g_{w}}{h_{0}}(1-C)+\Theta\left(-S_{h}\right) \frac{C}{2 h_{\mathrm{m}}} S_{h} \\
& +T_{R}^{-1}\left(C^{\mathrm{o}}-C\right) \\
\frac{\mathrm{d} h}{\mathrm{~d} t}= & S_{h}+N_{h}=g_{\mathrm{i}} C+(1-C) g_{\mathrm{w}}+f\left(T_{R}^{-1}\left(C^{\mathrm{o}}-C\right)\right) .
\end{aligned}
$$

The term $N_{C}$ in Eq. (13) assimilates (nudges) the idealised concentration observations $C^{\mathrm{o}}$ into the model with a relaxation time $T_{R}$ of 10 days. The term $N_{h}$ in Eq. (14) represents the different forms of the functional dependence between the mean-thickness analysis update and the concentration analysis update that we investigate (CMT or PMT).

In Appendices A2 and A3, we discuss in detail the dependence of ice growth on atmospheric forcing and ice concentration in this idealised model. Here, we focus on results from two concrete test cases, which illustrate problematic behaviour of concentration assimilation without vol- (a) Winter
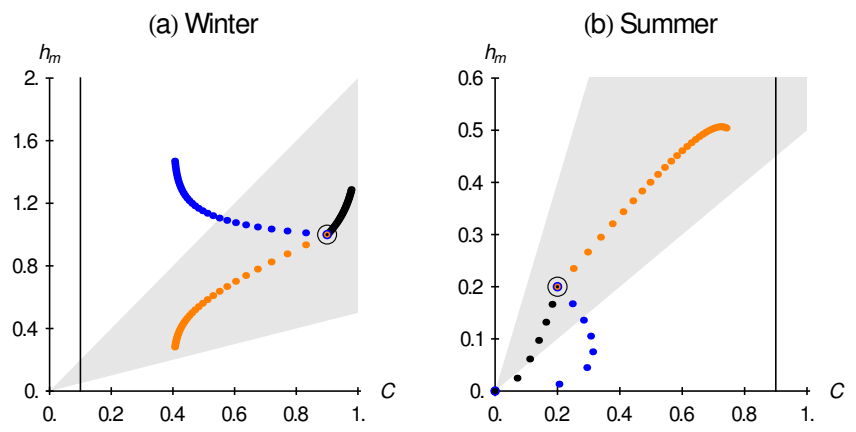

Fig. 6. Trajectories of the sea-ice state in the ice energy balance model with and without assimilation for one month of (a) constant winter forcing and (b) constant summer forcing. Positions for each day are marked by black points (trajectory without assimilation), blue points (trajectory with CMT assimilation), and orange points (trajectory with PMT assimilation). All trajectories start from the same initial conditions marked by the black circle. The target ice concentration is marked by a thin vertical line. The nudging parameters are as in the AOGCM experiments. Mean ice thickness for a given concentration in the AOGCM is typically within the grey shaded area.

ume correction (CMT). The first test case is the assimilation of low sea-ice concentration under winter conditions with a downwelling shortwave radiation of $0 \mathrm{~W} \mathrm{~m}^{-2}$ and downwelling longwave radiation of $220 \mathrm{~W} \mathrm{~m}^{-2}$. The second test case is the assimilation of high sea-ice concentration under summer conditions with a downwelling shortwave radiation of $160 \mathrm{~W} \mathrm{~m}^{-2}$ and downwelling longwave radiation of $300 \mathrm{~W} \mathrm{~m}^{-2}$.

Figure 6 shows the trajectories of $C$ and $h_{\mathrm{m}}$ without assimilation, with CMT assimilation and with PMT assimilation for both test cases. Within the grey area that underlies the trajectories, the joint probability of occurrence for $C$ and $h_{\mathrm{m}}$ is higher than $0.1 \%$, as diagnosed from a long AOGCM run. In the following, we will call this the region of plausible ice states.

For the winter test case (Fig. 6a), the trajectories start from high concentration and $1 \mathrm{~m}$ mean thickness. Since the forcing implies freezing conditions, both concentration and mean thickness increase when there is no nudging. When we nudge the model towards low ice concentration, the concentration initially decreases, but after one month the model and nudging tendencies for concentration almost compensate, and concentration stays constant at an intermediate level. For the mean ice thickness, we observe contrasting behaviour for PMT and CMT. The CMT trajectory still goes to higher thickness, and even outgrows the free trajectory. This is due to the concentration dependence of net growth rate described in Appendix A3. It therefore enters a state of low sea-ice concentration and high mean ice thickness, which is rather unphysical and not typically seen in the AOGCM. On the other hand, the PMT trajectory decreases mean ice thickness, and hence stays within the region of plausible ice states. 
Ice concentration
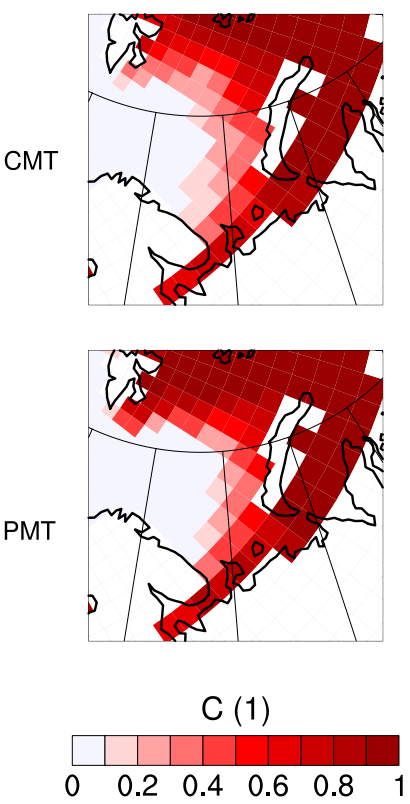

Mean ice thickness
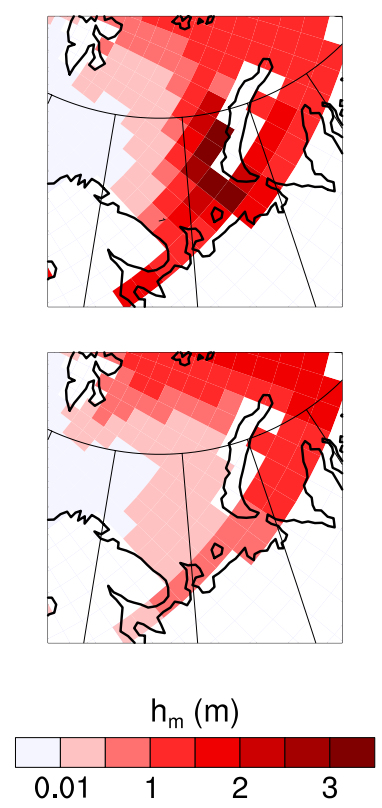

Fig. 7. Average March conditions 1990-1999 when assimilating observed sea-ice concentration in the AOGCM with the CMT method (top) and the PMT method (bottom). Ice concentration (left) is similar between CMT and PMT, and quite close to observations. However, mean ice thickness (right) is much too high for CMT, and realistic for PMT.

For the summer test case (Fig. 6b), we let the trajectories start at low concentration and $0.2 \mathrm{~m}$ mean thickness. The trajectory without the relaxation term goes to an ice-free state within 6 days. When we nudge towards high concentration, the behaviour of PMT and CMT is again very different. The CMT trajectory loses ice volume; because for constant forcing the concentration loss is higher for thinner ice (see Eq. 6), concentration only initially increases, but soon the thermodynamic tendency outweighs the nudging tendency. Consequently, the CMT trajectory becomes ice-free within seven days, even though the data assimilation aims at increasing the ice concentration. Note that the melt is somewhat slower than without data assimilation, in accordance with the dependence of growth rate on concentration discussed in Appendix A3. On the other hand, the PMT trajectory gains ice volume, and stays inside the region of plausible ice states for the whole month.

In the AOGCM, an indication for the problematic behaviour of the CMT method is found in the wintertime Barents Sea (Fig. 7). During the 1990's, the Barents Sea was mainly ice-free during winter, as derived from the satellite observations, whereas the model without assimilation is biased towards ice-covered conditions. With assimilation, the ice concentration in this area decreases, but the decreased concentration leads to enhanced thermodynamic ice growth rates. As a result, there is unrealistically high ice volume in conjunction with a reduced ice concentration if the CMT method is employed. Only when we apply PMT is this effect averted, as the nudging updates of ice volume compensate the excessive thermodynamic growth rates.

In summary, we have shown in this section that there are cases of practical relevance when the sea-ice growth rates as determined by the local surface energy balance necessitate adjustments of mean sea-ice thickness during the assimilation, as it is done in the CAT and PMT methods. This finding is consistent with results by Dulière and Fichefet (2007). Without these mean-thickness adjustments, as is the case for the CMT method, assimilation of ice concentration leads to implausible sea-ice states both in a conceptual IEBM and in the AOGCM.

\subsection{Statistical aspects - model error covariances and weight matrices}

We now take a different view on assimilation errors: instead of examining the sea-ice prognostic equations and how analysis updates affect them, we examine the covariance structure of thickness and concentration errors in the AOGCM. There is a well-established theory that connects these so-called model background errors with the optimal analysis update; see, for instance, Bouttier and Courtier (1999) or Kalnay (2003). The analysis updates we apply are not optimal, but are derived from the simple nudging approach. Nevertheless, we can map our different choices for the analysis update to different model background errors that are implied under the assumption of optimality. If the implied model background errors are clearly unrealistic, we can argue that the assimilation method is prone to fail, since it is far from being optimal. We follow the notation of Bouttier and Courtier (1999) and briefly introduce the basic terminology in Sect. 6.2.1. We then apply the general terminology to our setup in Sect. 6.2.2, devising simplifications and a specialised notation. These simplifications and the specialised notation allow us to concisely discuss in Sect. 6.2.3 the relation between concentration and mean thickness errors on the one hand and optimal analysis updates on the other hand.

\subsubsection{Introduction of terminology}

The state of a model that has $v$ variables and $p$ grid points is encoded in the state vector $\boldsymbol{x}$, a column vector with $p \cdot v$ entries. To obtain the analysis $\boldsymbol{x}_{\mathrm{a}}$, i.e. our estimate of the true state $\boldsymbol{x}_{\mathrm{t}}$, the model background $\boldsymbol{x}_{\mathrm{b}}$ is updated with a term that depends on the departure of the model state from the observations $y$ :

$\boldsymbol{x}_{\mathrm{a}}=\boldsymbol{x}_{\mathrm{b}}+\mathbf{K}\left(\boldsymbol{y}-\mathbf{H} \boldsymbol{x}_{\mathrm{b}}\right)$.

The observation operator $\mathbf{H}$ maps the $o$ observations to the vp-dimensional state vector $\boldsymbol{x}$ and therefore is a matrix with dimensions $o \times v p$. The $(v p \times o)$-dimensional matrix $\mathbf{K}$ determines how discrepancies between observations and the 
model state translate to analysis updates. It is called the gain, or weight matrix. If the weight matrix is chosen according to

$\mathbf{K}^{\mathrm{opt}}=\mathbf{B H}^{T}\left(\mathbf{H B} \mathbf{H}^{T}+\mathbf{R}\right)^{-1}$,

then the analysis in Eq. (15) is the best linear unbiased estimator of the true state (Bouttier and Courtier, 1999).

The optimal weight matrix $\mathbf{K}^{\mathrm{opt}}$ is related to the covariance matrices of background and observation errors $\mathbf{B}$ and $\mathbf{R}$, defined by

$\mathbf{B}=\left\langle\left(\boldsymbol{\epsilon}_{\mathrm{b}}-\overline{\boldsymbol{\epsilon}}_{\mathrm{b}}\right)\left(\boldsymbol{\epsilon}_{\mathrm{b}}-\overline{\boldsymbol{\epsilon}}_{\mathrm{b}}\right)^{T}\right\rangle \quad \mathbf{R}=\left\langle\left(\boldsymbol{\epsilon}_{\mathrm{o}}-\overline{\boldsymbol{\epsilon}}_{\mathrm{o}}\right)\left(\boldsymbol{\epsilon}_{\mathrm{o}}-\overline{\boldsymbol{\epsilon}}_{\mathrm{o}}\right)^{T}\right\rangle$.

The model background error $\boldsymbol{\epsilon}_{\mathrm{b}}=\boldsymbol{x}_{\mathrm{b}}-\boldsymbol{x}_{\mathrm{t}}$ describes the discrepancy between the modelled and the true state just before an analysis update. Therefore, $\boldsymbol{\epsilon}_{\mathrm{b}}$ depends not only on the error of the model itself, but also on the applied analysis updates and the time interval between them. The observation error $\boldsymbol{\epsilon}_{\mathrm{o}}=\boldsymbol{y}-\mathbf{H} \boldsymbol{x}_{\mathrm{t}}$ expresses that the reported value of an observation is not a perfect image of reality, but is distorted due to instrumental and discretisation errors. $\mathbf{B}$ has dimensions $p v \times p v$, and $\mathbf{R}$ has dimensions $o \times o$.

\subsubsection{Application to ice concentration and thickness}

After introducing the general terminology, we now apply it to our setup. Because the simplicity of the setup allows for several algebraic simplifications, we can derive concise expressions that are useful for understanding the interplay between ice thickness and ice concentration errors. We order the state vector $x$ so that it starts with the entries for ice concentration $C$ and ice mean thickness $h$, followed by all other model variables:

$\boldsymbol{x}=\left(C_{1}, \ldots, C_{\mathrm{p}}, h_{1}, \ldots, h_{\mathrm{p}}, \ldots\right)^{T}$.

Sea-ice concentration is the only variable observed, and we are not interested in issues related to the interpolation from observation points to model points. Thus, we can assume a very simple form for the observation operator:

$\mathbf{H}=\left(\begin{array}{lll}\mathbf{I} & \mathbf{0} & \ldots\end{array}\right)$,

with $\mathbf{I}$ denoting the $p \times p$ identity matrix and $\mathbf{0}$ denoting the $p \times p$ zero matrix. Furthermore, the observation error covariance matrix $\mathbf{R}$ reduces to the $p \times p$ matrix $\mathbf{R}_{\mathrm{CC}}$.

We partition the background error covariance matrix $\mathbf{B}$ and the weight matrix $\mathbf{K}$ into submatrices of dimension $p \times p$ that respectively describe the covariance between each pair of variables in the model, and the gains for each model variable resulting from the concentration observations:

$\mathbf{B}=\left(\begin{array}{ccc}\mathbf{B}_{\mathrm{CC}} & \mathbf{B}_{\mathrm{hC}} & \cdots \\ \mathbf{B}_{\mathrm{Ch}} & \mathbf{B}_{\mathrm{hh}} & \cdots \\ \vdots & \vdots & \ddots\end{array}\right) \quad \mathbf{K}=\left(\begin{array}{c}\mathbf{K}_{\mathrm{CC}} \\ \mathbf{K}_{\mathrm{Ch}} \\ \vdots\end{array}\right)$.
Using Eqs. (18) to (20), the analysis update in Eq. (15) can be written as:

$$
\left(\begin{array}{c}
\boldsymbol{C}_{\mathrm{a}} \\
\boldsymbol{h}_{\mathrm{a}} \\
\vdots
\end{array}\right)=\left(\begin{array}{c}
\boldsymbol{C}_{\mathrm{b}} \\
\boldsymbol{h}_{\mathrm{b}} \\
\vdots
\end{array}\right)+\left(\begin{array}{c}
\mathbf{K}_{\mathrm{CC}} \\
\mathbf{K}_{\mathrm{Ch}} \\
\vdots
\end{array}\right)\left(\boldsymbol{C}_{o}-\boldsymbol{C}_{\mathrm{b}}\right)
$$

and the optimal weight matrix (Eq. 16) reduces to a form that shows how the concentration and thickness background errors enter the optimal weight matrix:

$\mathbf{K}^{\mathrm{opt}}=\left(\begin{array}{c}\mathbf{B}_{\mathrm{CC}} \\ \mathbf{B}_{\mathrm{Ch}} \\ \vdots\end{array}\right)\left(\mathbf{B}_{\mathrm{CC}}+\mathbf{R}_{\mathrm{CC}}\right)^{-1}$.

Equation (22) tells us how to obtain the optimal analysis update when we already know the correct statistics of the background and observation errors. Determining these error statistics is a difficult task within the data assimilation framework. Here, we are only interested in conceptual statements that can be derived from the error covariances, and so we estimate them using simplifying assumptions. We assume that the observation error covariance $\mathbf{R}_{\mathrm{CC}}$ is spatially uncorrelated and corresponds to a constant uncertainty of $10 \%$.

This value is a reasonable average error for concentration observation according to Tonboe and Nielsen (2010). We estimate the background error covariances $\mathbf{B}_{\mathrm{CC}}$ and $\mathbf{B}_{\mathrm{Ch}}$ from the daily differences between concentration and thickness of two long, independent AOGCM runs. These background errors apply when the time interval between analysis updates is very large. For shorter time intervals between the analysis updates (one day for our setup), the absolute magnitude of the covariances is smaller, but we expect their spatial structure to be the same. For instance, in the central Arctic the seaice concentration is usually high, and thus we expect a low concentration background error variance, whereas we expect substantial background error covariance in areas that experience a pronounced seasonal cycle of both thickness and concentration.

From the model background error covariances we can also derive the correlation between concentration and thickness errors at the location $P$ :

$\operatorname{corr}_{\mathrm{P}}(C, h)=\frac{\mathbf{B}_{\mathrm{Ch}}(P)}{\sqrt{\mathbf{B}_{\mathrm{CC}}(P) \mathbf{B}_{\mathrm{hh}}(P)}}$.

For the central Arctic, the correlation between concentration and thickness errors is between 0.3 and 0.5 , whereas it is always higher than 0.5 in the seasonal ice zones. We find a pan-Arctic average over the concentration and thickness correlation of 0.7 , which is similar to the correlations reported by Lisæter et al. (2003) and Zhang (2010). In hindsight, this high correlation between background errors in concentration and thickness justifies the proportionality assumption in the PMT method stated in Eq. (11). 

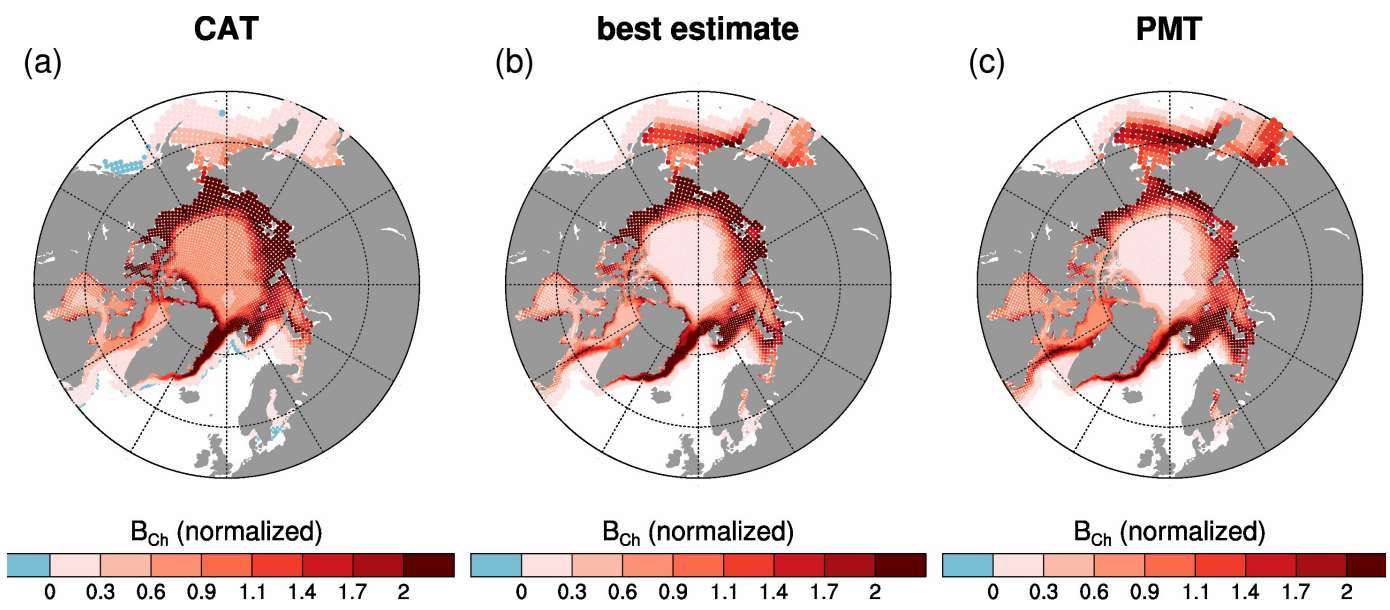

Fig. 8. Scaled diagonal elements of the background model error covariance matrices; (a) derived from Eq. (26) when analysis updates conserve actual thickness; (b) best estimate from a long free model run, and (c) derived from Eq. (27) for proportional mean-thickness analysis updates. The background error covariance implied by analysis updates that conserve mean thickness is zero everywhere. For an interpretation of the figure see main text.

\subsubsection{Comparing nudging with optimal analysis updates}

For the analysis updates of mean thickness, Eq. (22) defines the optimal weight matrix

$\mathbf{K}_{\mathrm{Ch}}^{\mathrm{opt}}=\mathbf{B}_{\mathrm{Ch}}\left(\mathbf{B}_{\mathrm{CC}}+\mathbf{R}_{\mathrm{CC}}\right)^{-1}$.

In our setup, we use weight matrices derived not from the optimality condition, but from an ad hoc nudging approach. Nevertheless, we can ask the following question: "Suppose the weight matrix $\mathbf{K}_{\mathrm{Ch}}^{X}$ used in method $X$ is optimal, and we know the background error covariance for concentration $\mathbf{B}_{\mathrm{CC}}$, what would be the implied background error covariance between concentration and thickness $\mathbf{B}_{\mathrm{Ch}}^{X}$ ?" If $\mathbf{B}_{\mathrm{Ch}}^{X}$ is unrealistic, i.e. has substantial deviations from $\mathbf{B}_{\mathrm{Ch}}$, we can conclude that the weight matrix is far from being optimal and we reject an assimilation scheme that uses this weight matrix as being inconsistent.

For CMT, we do not update mean thickness at all, and so:

$\mathbf{K}_{\mathrm{Ch}}^{\mathrm{CMT}}=0 \stackrel{\text { Optimality }}{\Longleftrightarrow} \mathbf{B}_{\mathrm{Ch}}^{\mathrm{CMT}}=0$.

For CAT, we see from Eq. (10) that nudging weights vary in time and space, depending on the background actual thickness. We derive a time-averaged analysis update by diagnosing a diagonal matrix $\mathbf{h}_{\mathrm{t}}$ that contains the time average of actual ice thickness at each grid point over a long model run on the diagonal. With this, the average weight matrix and implied background error covariance are

$\mathbf{K}_{\mathrm{Ch}}^{\mathrm{CAT}}=\mathrm{K}_{\mathrm{N}} \mathbf{h}_{\mathrm{t}} \stackrel{\text { Optimality }}{\Longleftrightarrow} \mathbf{B}_{\mathrm{Ch}}^{\mathrm{CAT}}=\mathrm{K}_{\mathrm{N}} \mathbf{h}_{\mathrm{t}}\left(\mathbf{B}_{\mathrm{CC}}+\mathbf{R}_{\mathrm{CC}}\right)$.

Finally, for PMT the weights are constant, because they are determined by $h^{*}$ from Eq. (11). The weight matrix together with its implied background error covariance matrix is given by

$\mathrm{K}_{\mathrm{Ch}}^{\mathrm{PMT}}=\mathrm{K}_{\mathrm{N}} h^{*} \mathbf{I} \stackrel{\text { Optimality }}{\Longleftrightarrow} \mathbf{B}_{\mathrm{Ch}}^{\mathrm{PMT}}=\mathrm{K}_{\mathrm{N}} h^{*}\left(\mathbf{B}_{\mathrm{CC}}+\mathbf{R}_{\mathrm{CC}}\right)$.

The different background error covariances are compared in Fig. 8 by showing maps of their scaled diagonal elements. The absolute values of the covariances are not important, since they depend on the time interval between the analysis updates. However, the spatial distribution of high and low covariances has a large influence on the assimilation performance, as it determines the relative strengths of the optimal weights.

From Fig. 8b we see that background error covariances should be low in the perennial ice zone of the central Arctic, since there the concentration is always high, and low at the southern edge of the seasonal ice zone, since there the mean ice thickness is always low. In between, there is a region where mean ice thickness and ice concentration co-vary strongly.

The CMT analysis updates imply a covariance structure that is very different from our best guess of the true covariance structure: it is zero everywhere. This implies a perfect representation of thickness forecasts in the model, which is a bad assumption, as we have seen in Sect. 6.1. Therefore, the CMT weight matrix is far from being optimal. Already from this simple analysis of background error covariance, one could have expected the poor assimilation performance seen in Sects. 4 and 5.

The CAT updates imply a covariance structure that resembles our best guess reasonably well, so that one would expect a useful assimilation performance (Fig. 8a). However, some discrepancies stand out: The implied thicknessconcentration covariance is too high in the central Arctic, indicating that the weights for updating mean thickness are too 
large there. On the other hand, the implied covariance is too low in the Bering Sea, the Labrador Sea, and the Barents Sea. One would expect the method to have difficulties assimilating observations there, since the analysis weights are too small.

Finally, the PMT updates shown in Fig. 8c imply a concentration-thickness covariance structure that is close to our best guess. There is a tendency to underestimate covariance in the Arctic shelf seas, and to overestimate it in the Hudson and Baffin Bays, but overall there is good agreement.

We conclude that the comparison of the background error covariances implied by the chosen nudging weight matrices $\mathbf{K}_{\mathrm{Ch}}$ corroborates the experimentally found differences between the assimilation performance of the CMT, CAT, and PMT methods. Moreover, we think that the examination of implied background error covariance is a useful guide for designing weight matrices: only if the implied background error covariance looks plausible, can we expect a good performance of the assimilation method.

\section{Summary and conclusion}

We examine the performance of sea-ice data assimilation in a global climate model, using a simple Newtonian relaxation approach. Analysis updates of sea-ice concentration are derived from the discrepancy between model and observations, and analysis updates of sea-ice mean thickness (i.e. volume) are derived from the concentration updates. We investigate three different approaches for the mean-thickness analysis updates. The first approach keeps the mean thickness constant during the analysis update (CMT). The second approach keeps the actual ice thickness constant (CAT). CMT and CAT have been suggested and used before in seaice data assimilation in an ice-ocean model (Dulière and Fichefet, 2007), but we find that with our assimilation setup in an AOGCM they do not give satisfying results. Therefore, we introduce a third approach, which prescribes a fixed proportionality between concentration updates and mean thickness updates (PMT).

We establish four independent lines of evaluation by (i) comparing the simulated ice concentration and extent with observations, (ii) comparing simulated ice concentration and thickness with a reference simulation in an identical-twin experiment, (iii) considering conceptual arguments about the local ice energy balance, and (iv) considering the statistics of model background errors.

We find that PMT has much lower assimilation errors than the other two methods. For synthetic observation data derived from output of the same model (identical-twin study), PMT reduces the error of year-to-year changes in annual mean sea-ice extent to less than $0.1 \times 10^{6} \mathrm{~km}^{2}$, the error in annual mean sea-ice volume to $600 \mathrm{~km}^{3}$, the gridpoint-wise error in ice concentration to below $5 \%$ throughout the year, and the gridpoint-wise error in mean ice thickness in the Arc- tic Ocean to less than $30 \mathrm{~cm}$. In contrast to these significant improvements, the impact of the assimilation on simulating other Arctic surface fields like sea-surface salinity and surface air temperature is only weak.

For the assimilation of observed sea-ice concentration between 1979 and 2007, the PMT assimilation significantly reduces differences between modelled and observed ice extent and concentration, with deviations becoming almost as low as in the identical-twin study. The monthly mean sea-ice volume between 2005 and 2008 in the PMT assimilation is in good agreement with volume estimates derived from ICESat observations and the PIOMAS reanalysis, with deviations of less than $2000 \mathrm{~km}^{3}$.

The simplicity of the assimilation scheme allows us to examine the assimilation errors with two conceptual tools: first, we apply the assimilation to a simple model of the local ice energy balance and conclude that the CMT method, where no adjustments to the mean thickness are made during the analysis update, causes unacceptable assimilation errors.

Second, we analyse the spatial structure of the background error covariance between concentration and thickness as implied by the nudging weight matrices of the different methods and find that the spatial structure of the background error is unrealistic for CMT, reasonable with some deficiencies for CAT, and realistic for PMT. These conceptual arguments support our experimental finding that the PMT method outperforms both CMT and CAT.

A drawback of our simple assimilation approach is that the model equations are not used in the analysis step, as they would be in four-dimensional variational data assimilation. Therefore, inconsistencies between our analysis updates and model physics are expected to occur, a property shared with several other data assimilation approaches. Our results show, however, that the parameters of our simple assimilation approach can be chosen such that we obtain improvement of both ice concentration and ice thickness, and that we understand why some methods work better than others. Therefore we conclude that skillful sea-ice initialisation in an AOGCM is possible from ice-concentration data even with a simple Newtonian relaxation scheme, provided that we choose an appropriate functional relationship between concentration and mean-thickness analysis updates.

\section{Appendix A}

\section{A simple radiative energy balance model for sea-ice mean thickness and concentration}

\section{A1 Derivation of the simple model}

We discuss the equations for the sea-ice thermodynamics as they are implemented in ECHAM5/MPI-OM. After several simplifications we arrive at a closed set of prognostic 


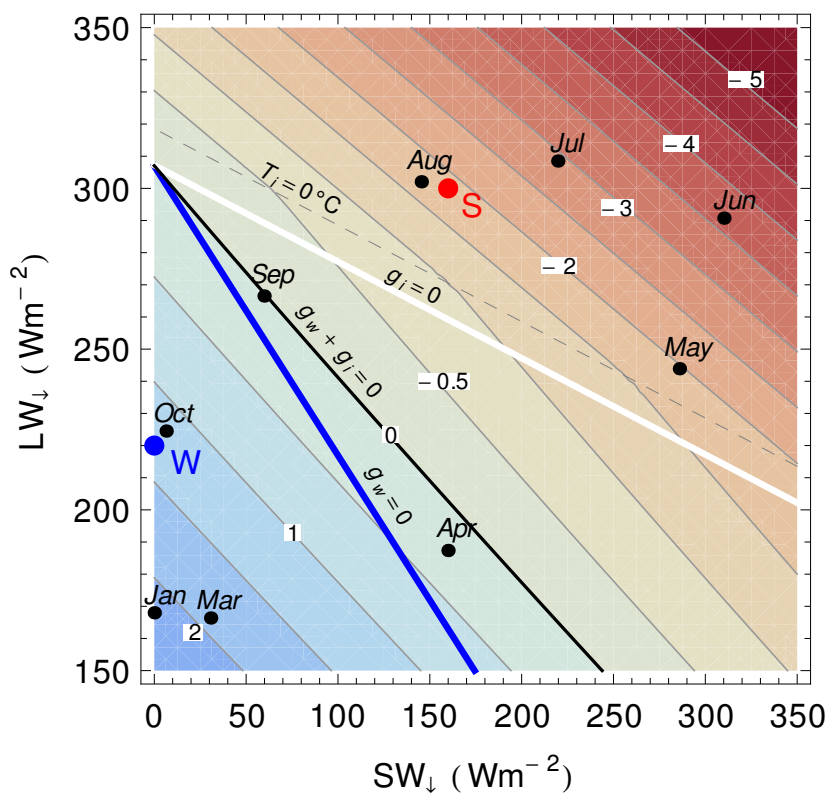

Fig. 9. Contour plot of ice growth rates in $\mathrm{cm} \mathrm{day}^{-1}$ for mean ice thickness $h_{\mathrm{m}}=1 \mathrm{~m}$ and ice concentration $C=0.7$. On the xaxis is the downwelling shortwave radiation, on the y-axis the downwelling longwave radiation. The black dots correspond to the typical monthly-mean forcing in the Arctic according to Maykut and Untersteiner (1971). The blue and white lines mark the zerocrossing of the growth rates for open water and over ice, which are independent of the state of the ice. The thick black line is the zero-crossing of net growth rate, and depends on the state of the ice. At the dashed grey line, the ice surface temperature is at the melting point of $0{ }^{\circ} \mathrm{C}$. The larger blue and red dots, labelled "W" and "S", mark typical winter and summer conditions, for which the conditional probability distributions of growth rate in Fig. 10 are calculated.

equations for the ice concentration $C$ and mean ice thickness $h_{\mathrm{m}}$. These equations constitute a simple ice-energy-balance model (IEBM), which we use to analyse the ice growth rate for different atmospheric forcing regimes and to study how the analysis updates affect the thermodynamics of the ice.

The first simplification we make is to neglect sea-ice advection. Since melting and freezing of ice are local processes, we can then solve the prognostic equations for mean thickness (Eq. 1) and concentration (Eq. 2) for each point in space separately. The thermodynamic source terms for sea-ice mean thickness $S_{h}$ (Eq. 5) and sea-ice concentration $S_{C}$ (Eq. 6) are determined by a balance of atmospheric and oceanic heat fluxes at the sea-ice interfaces. An oceanic heat flux is established when sea-water warmer than the freezing temperature is brought into contact with the ice, while an atmospheric heat flux occurs at the interface between atmosphere and sea ice or open water.

Since the dominant contribution to the sea-ice energy balance in the Arctic is typically the surface radiation (Maykut and Untersteiner, 1971; Serreze et al., 2007), we neglect
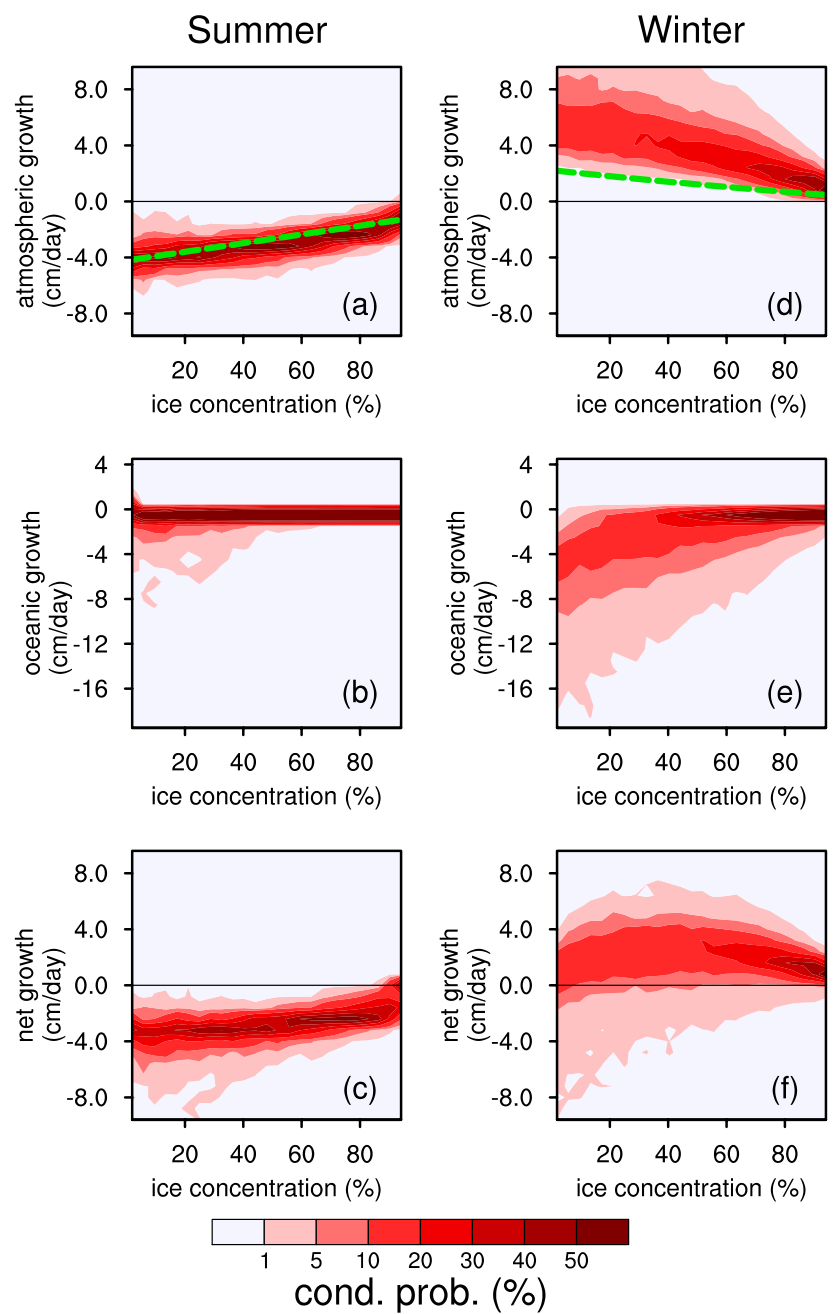

Fig. 10. Conditional probability densities with which heat fluxes contributing to sea-ice growth occur for a given sea-ice concentration. The occurrence probabilities were diagnosed from a long run of ECHAM5/MPI-OM for representative summer (a-c) and winter (d-f) conditions. Heat fluxes are given as equivalent ice growth rates $\left(1 \mathrm{~cm} \mathrm{day}^{-1}=35 \mathrm{~W} \mathrm{~m}^{-2}\right)$. Heat fluxes shown in (a and $\left.\mathbf{d}\right)$ are between the ice and the atmosphere, and in (b and $\mathbf{e})$ between the ice and the ocean. (c and $\mathbf{f}$ ) show the net growth rates of the sea ice, which are equivalent to the sum of atmospheric and oceanic heat flux into the ice. The dashed green line is the dependence found in the simple radiative ice-energy balance model.

oceanic and turbulent atmospheric heat fluxes as a first approximation and determine the ice growth rates from the radiative balance:

$g_{\mathrm{w}, \mathrm{i}}=-\frac{1}{\rho L}\left(\left(1-\alpha_{\mathrm{w}, \mathrm{i}}\right) \mathrm{SW}_{\downarrow}+\mathrm{LW}_{\downarrow}-\sigma T_{\mathrm{w}, \mathrm{i}}^{4}\right)$.

The subscript " $w$ " denotes the open-water part of the surface, and " $\mathrm{i}$ " denotes the ice-covered part. Heat fluxes are converted to growth rates by dividing by the negative product of sea-ice density $\rho$ and latent heat of fusion for water $L$. 
$\mathrm{SW}_{\downarrow}$ and $\mathrm{LW}_{\downarrow}$ are the downwelling shortwave and longwave radiation at the surface, and $\alpha_{\mathrm{w}, \mathrm{i}}$ is the albedo of open water or sea ice. In ECHAM5/MPI-OM, the surface temperature of open water in a partly ice-covered grid cell is always at a representative sea-water freezing temperature $T_{\mathrm{w}}=-1.9^{\circ} \mathrm{C}$, and the ice surface temperature $T_{\mathrm{i}}$ is calculated from the balance of heat fluxes at the ice surface. We prescribe the atmospheric downwelling radiation as an external forcing and determine $S_{h}$ and $S_{C}$ as a function of ice state and forcing. Thereby, we can convert Eqs. (1) and (2) into a closed set of two coupled ordinary differential equations, which are forced by the time-dependent downwelling radiation at the surface.

To obtain a closed set of equations using Eqs. (1), (2), (5) (6) and (A1), we need to determine how the growth rates $g_{\mathrm{w}}$ and $g_{i}$ depend on the forcing, i.e. downwelling longwave and shortwave radiation at the surface, and the state of the ice, i.e. concentration and mean thickness. These growth rates are directly proportional to the heat fluxes $q_{\mathrm{w}, \mathrm{i}}$ via

$g_{\mathrm{w}, \mathrm{i}}=-\frac{1}{\rho L} q_{\mathrm{w}, \mathrm{i}}$.

The heat flux over open water in a partly ice-covered grid cell, $q_{\mathrm{w}}$, is easy to determine: the temperature of that open water is at the freezing point, so that the upwelling longwave radiation is constant. The heat flux over ice, $q_{\mathrm{i}}$, is more difficult, since it depends on the ice surface temperature $T_{\mathrm{i}}$. The ice surface temperature has to be determined from the balance of the heat flux at the ice surface $q_{\mathrm{i}}$ with the conductive heat flux through the ice $q_{\mathrm{c}}$ and a residual heat flux $q_{\mathrm{r}}$ that goes into surface melt:

$q_{\mathrm{i}}=q_{\mathrm{c}}+q_{\mathrm{r}}$.

The conductive heat flux through the ice is assumed to be proportional to the difference between the temperature at the top of the ice $T_{\mathrm{i}}$ and the temperature at the bottom, which is always at the freezing temperature $T_{\mathrm{f}}$. This is the so-called 0-layer model for ice growth suggested by Semtner (1976). The proportionality constant is the heat conductivity of ice $k$ divided by the actual ice thickness $h_{\mathrm{t}}=h_{\mathrm{m}} / C$. The conductive heat flux as a function of ice surface temperature then is

$q_{C}\left(T_{\mathrm{i}}\right)=\frac{k C}{h_{\mathrm{m}}}\left(T_{\mathrm{i}}-T_{\mathrm{f}}\right)$.

In our model, sea ice is assumed to melt at the freshwater melting temperature $T_{\mathrm{m}}=0^{\circ} \mathrm{C}$ at the top. When $T_{\mathrm{i}}<$ $T_{\mathrm{m}}$, there is no surface melt, $q_{\mathrm{r}}=0$, and $T_{\mathrm{i}}$ can be derived from $q_{\mathrm{i}}=q_{\mathrm{c}}$. With a linearisation of the black-body radiation around $T_{\mathrm{m}}$, we can solve for $T_{\mathrm{i}}$ and obtain

$T_{\mathrm{i}}=\frac{T_{\mathrm{f}} k C / h_{\mathrm{m}}+\left(1-\alpha_{\mathrm{i}}\right) \mathrm{SW}_{\downarrow}+\mathrm{LW}_{\downarrow}+3 \sigma T_{\mathrm{m}}^{4}}{k C / h_{\mathrm{m}}+4 \sigma T_{\mathrm{m}}^{3}}$.

The ice surface temperature cannot get larger than $T_{\mathrm{m}}$ in the model, because for $T_{\mathrm{i}}=T_{\mathrm{m}}$ the residual heat flux be- comes larger than zero, $q_{\mathrm{r}}>0$, and melts ice at the surface:

$$
\begin{aligned}
\left.q_{\mathrm{r}}\right|_{T_{\mathrm{i}}=T_{\mathrm{m}}} & =q_{\mathrm{i}}\left(T_{\mathrm{m}}\right)-q_{\mathrm{c}}\left(T_{\mathrm{m}}\right)=\left(1-\alpha_{\mathrm{i}}\right) \mathrm{SW}_{\downarrow}+\mathrm{LW}_{\downarrow} \\
& -\sigma T_{\mathrm{m}}^{4}-\frac{k C}{h_{\mathrm{m}}}\left(T_{\mathrm{m}}-T_{\mathrm{f}}\right) .
\end{aligned}
$$

Inserting Eqs. (A4) and (A6) into Eq. (A3), we can write the net heat flux into the ice-covered part of the cell in a compact form:

$$
\begin{aligned}
q_{\mathrm{i}} & =\frac{k C}{h_{\mathrm{m}}}\left(T_{\mathrm{i}}-T_{\mathrm{f}}\right)+\delta\left(T_{\mathrm{i}}-T_{\mathrm{m}}\right)\left(-\frac{k C}{h_{\mathrm{m}}}\left(T_{\mathrm{m}}-T_{\mathrm{f}}\right)+\left(1-\alpha_{\mathrm{i}}\right) \mathrm{SW}_{\downarrow}\right. \\
& \left.+\mathrm{LW}_{\downarrow}-\sigma T_{\mathrm{m}}^{4}\right)
\end{aligned}
$$

With this, we arrive at the following set of prognostic equations for the mean ice thickness $h_{\mathrm{m}}$ and the ice concentration $C$ :

$\frac{\mathrm{d} h_{\mathrm{m}}}{\mathrm{d} t}=g_{\mathrm{i}} C+(1-C) g_{\mathrm{w}}$
$\frac{\mathrm{d} C}{\mathrm{~d} t}=\Theta\left(g_{\mathrm{w}}\right) \frac{g_{\mathrm{w}}}{h_{0}}(1-C)+\Theta\left(-S_{h}\right) \frac{C}{2 h_{\mathrm{m}}} S_{h}$,

where we can use Eqs. (5), (6), and Eqs. (A1-A7) to express each term on the right-hand side as a function only of the prognostic variables $h_{\mathrm{m}}$ and $C$ and the external forcings $\mathrm{SW}_{\downarrow}$ and $\mathrm{LW}_{\downarrow}$.

\section{A2 Dependence of ice growth on atmospheric forcing}

With Eq. (A1) we have an explicit expression for the ice growth rate, and we can study how it depends on the atmospheric forcing. If we are able to identify forcing regimes that differ among each other in the way the sea-ice thermodynamics reacts to changes in concentration, we will have important information for assessing the effects of the data assimilation on the prognostic equations.

Figure 9 shows the net growth rates derived from the IEBM for a sea-ice state of $1 \mathrm{~m}$ mean thickness and $70 \%$ concentration. We can identify three different regimes, which are separated by the zero-growth contour over open water $g_{\mathrm{w}}=0$ and the zero-growth contour over ice $g_{\mathrm{i}}=0$. Importantly, the zero-growth contours are independent of the state of the ice and constitute the boundaries between three different forcing regimes.

In the winter regime, freezing occurs both over ice and over open water $\left(g_{\mathrm{w}}>0, g_{\mathrm{i}}>0\right)$. In this regime, shortwave absorption is negligible, and the longwave heat loss over open water is much stronger than over ice, which leads to $g_{\mathrm{w}}>g_{\mathrm{i}}$. It therefore follows from Eq. (5) that the net ice growth rate $g$ decreases for increasing concentration. In the transitional regime, growth rates are generally small. Over open water there is net heating leading to a negative growth rate of the adjacent ice, whereas growth rate over ice is positive $\left(g_{\mathrm{w}}<0, g_{\mathrm{i}}>0\right)$. In the summer regime, both over open water and over ice there is net heating that leads to ice melt $\left(g_{\mathrm{w}}<0, g_{\mathrm{i}}<0\right)$. Over ice, there is less shortwave absorption than over open water, whereas longwave heat fluxes are 
small. This implies $g_{\mathrm{w}}<g_{\mathrm{i}}$, and therefore the net growth rate increases with increasing concentration.

\section{A3 Dependence of ice growth on ice concentration}

To quantify the dependence of growth rate on ice concentration, we select two representative forcing conditions: one for winter with $\mathrm{SW}_{\downarrow}=0 \mathrm{~W} \mathrm{~m}^{-2}$ and $\mathrm{LW}_{\downarrow}=220 \mathrm{~W} \mathrm{~m}^{-2}$ (marked with a blue dot in Fig. 9), and one for summer with $\mathrm{SW}_{\downarrow}=160 \mathrm{~W} \mathrm{~m}^{-2}$ and $\mathrm{LW}_{\downarrow}=300 \mathrm{~W} \mathrm{~m}^{-2}$ (marked with a red dot in Fig. 9). We calculate growth rates from the radiative budget of the IEBM described above, but there are two other contributions to the growth rate that we have neglected so far: the sensible and latent atmospheric heat flux, and the oceanic heat flux. Capturing these effects goes beyond the scope of the IEBM, but we can diagnose them from dailymean fields of a long AOGCM run.

Figure 10 shows a synthesis of ice growth rates derived from the IEBM, and the occurrence of ice growth rates as diagnosed from the AOGCM. During summer (Fig. 10a-c), the single curve obtained from the IEBM approximates the occurrence of growth rates diagnosed from the AOGCM quite well, implying that oceanic contributions to ice melt as well as turbulent atmospheric heat fluxes are negligible. This is readily explained since the temperature of the near-surface atmosphere is close to the melting point, so that turbulent heat fluxes at the surface are small. At the same time, the ocean surface is warmed and becomes fresher, so that it gains buoyancy, and therefore convection is inhibited. Both in the IEBM and in the AOGCM, we observe a strong dependence of net ice growth rate on concentration: for the chosen atmospheric summer forcing, ice melts at the rate of $1 \mathrm{~cm}$ per day for $100 \%$ ice concentration, whereas it melts at a rate of more than $4 \mathrm{~cm}$ per day for very low ice concentration.

In winter, the IEBM is not a good approximation to the sea-ice thermodynamics in the AOGCM. As Fig. 10d shows, the curve determined from the radiative budget in the IEBM is actually at the lower boundary of the probability distribution of atmospheric growth rates. For open-water conditions, the IEBM predicts an atmospheric growth rate of $2 \mathrm{~cm}$ per day, whereas the most frequent value in the AOGCM is $5 \mathrm{~cm}$ per day, and even values of $8 \mathrm{~cm}$ per day occur quite often. The missing contribution comes from the turbulent atmospheric heat flux, which can be very large over open water during winter. Only if the near-surface atmosphere stratification is very stable and near-surface winds are very weak, does the turbulent heat flux become so small that the AOGCM exhibits the dependence derived from the radiation budget in the IEBM.

Additionally, in winter the oceanic contribution to ice growth becomes large (Fig. 10e). The oceanic contribution can be due to horizontal advection of warm water under the ice, upwelling of warm water through Ekman suction, or entrainment of warm water when the surface mixed layer deepens. The model shows high ocean-ice heat fluxes predom- inantly close to the ice edge. The diagnostic we use does not differentiate between the processes, but we believe that the major contribution comes from entrainment of warm water from below during the deepening of the surface mixed layer. As Lemke (1987) pointed out, especially at the onset of freezing the convection can be vigorous enough to explain the magnitude of the ocean-ice heat flux that we see in the model.

For low ice concentration in winter, the ocean-ice heat flux strongly inhibits ice growth. The most frequent value of the ocean-ice heat flux, expressed as an equivalent melt rate, is $4 \mathrm{~cm}$ day, and even much larger values are possible (Fig. 10e). This compensates the large atmosphere-ice heat flux (Fig. 10d), so that the net growth rate in winter depends only weakly on the concentration (Fig. 10f). Nevertheless, since sea ice is closely coupled to the surface mixed layer below, it is the heat content of the coupled system of sea ice and surface mixed layer that is essential for the evolution of the ice. This heat content is determined by the atmospheric heat flux, and we therefore argue that the atmospheric growth rate in winter is more important than the net growth rate. The heat that goes from the mixed layer into the ice and inhibits ice growth cools the sea-water, so that ice formation is affected at a later time.

Acknowledgements. We thank Thorsten Mauritsen and Jaison T. Ambadan for helpful discussions and two anonymous reviewers for thoughtful comments that helped improve the manuscript. This work was supported by the Max Planck Society for the Advancement of Science and the International Max Planck Research School on Earth System Modelling. All simulations were performed at the German Climate Computing Center (DKRZ) in Hamburg, Germany.

The service charges for this open access publication have been covered by the Max Planck Society.

Edited by: J. Schröter

\section{References}

Blanchard-Wrigglesworth, E., Armour, K. C., Bitz, C. M., and DeWeaver, E.: Persistence and inherent predictability of Arctic sea ice in a GCM ensemble and observations, J. Climate, 24, 231-250, doi:10.1175/2010JCLI3775.1, 2011a.

Blanchard-Wrigglesworth, E., Bitz, C. M., and Holland, M. M.: Influence of initial conditions and climate forcing on predicting Arctic sea ice, Geophys. Res. Lett., 38, L18503, doi:10.1029/2011GL048807, 2011b.

Bouttier, F. and Courtier, P.: Data assimilation concepts and methods - training course lecture notes, from http://www.ecmwf.int (last access: 11 January 2013), 1999.

Budikova, D.: Role of Arctic sea ice in global atmospheric circulation: A review, Global Planet. Change, 68, 149-163, doi:10.1016/j.gloplacha.2009.04.001, 2009. 
Cavalieri, D., Parkinson, C., Gloersen, P., and Zwally, H. J.: Sea Ice Concentrations from Nimbus-7 SMMR and DMSP SSM/I Passive Microwave Data, from http://nsidc.org/data/nsidc-0051. html (last access: 11 January 2013), 2008.

Dulière, V. and Fichefet, T.: On the assimilation of ice velocity and concentration data into large-scale sea ice models, Ocean Sci., 3, 321-335, doi:10.5194/os-3-321-2007, 2007.

Francis, J. A. and Vavrus, S. J.: Evidence linking Arctic amplification to extreme weather in mid-latitudes, Geophys. Res. Lett., 39, L06801, doi:10.1029/2012GL051000, 2012.

Hibler III, W. D.: A Dynamic Thermodynamic Sea Ice Model, J. Phys. Oceanogr., 9, 815-846, 1979.

Holland, M. M., Bailey, D. A., and Vavrus, S.: Inherent sea ice predictability in the rapidly changing Arctic environment of the Community Climate System Model, version 3, Clim. Dynam., 36, 1239-1253, doi:10.1007/s00382-010-0792-4, 2011.

Honda, M., Inoue, J., and Yamane, S.: Influence of low Arctic sea ice minima on anomalously cold Eurasian winters, Geophys. Res. Lett., 36, L08707, doi:10.1029/2008GL037079, 2009.

Hurrell, J., Meehl, G. A., Bader, D., Delworth, T. L., Kirtman, B., and Wielicki, B.: A Unified Modeling Approach to Climate System Prediction, Bull. Amer. Meteor. Soc., 90, 1819-1832, doi:10.1175/2009BAMS2752.1, 2009.

Jungclaus, J. H., Keenlyside, N., Botzet, M., Haak, H., Luo, J.J., Latif, M., Marotzke, J., Mikolajewicz, U., and Roeckner, E.: Ocean Circulation and Tropical Variability in the Coupled Model ECHAM5/MPI-OM, J. Climate, 19, 3952-3972, 2006.

Kalnay, E.: Atmospheric Modeling, Data Assimilation and Predictability, Cambridge University Press, 2003.

Koenigk, T., Mikolajewicz, U., Haak, H., and Jungclaus, J.: Variability of Fram Strait sea ice export: causes, impacts and feedbacks in a coupled climate model, Clim. Dynam., 26, 17-34, doi:10.1007/s00382-005-0060-1, 2006.

Koldunov, N. V., Stammer, D., and Marotzke, J.: Present-Day Arctic Sea Ice Variability in the Coupled ECHAM5/MPI-OM Model, J. Climate, 23, 2520-2543, doi:10.1175/2009JCLI3065.1, 2010.

Kwok, R., Cunningham, G. F., Wensnahan, M., Rigor, I., Zwally, H. J., and Yi, D.: Thinning and volume loss of the Arctic Ocean sea ice cover: 2003-2008, J. Geophys. Res., 114, C07005, doi:10.1029/2009JC005312, 2009.

Lemke, P.: A Coupled One-Dimensional Sea Ice-Ocean Model, J. Geophys. Res., 92, 13164-13172, 1987.

Levermann, A., Mignot, J., Nawrath, S., and Rahmstorf, S.: The Role of Northern Sea Ice Cover for the Weakening of the Thermohaline Circulation under Global Warming, J. Climate, 20, 4160-4171, doi:10.1175/JCLI4232.1, 2007.

Lindsay, R. W. and Zhang, J.: Assimilation of Ice Concentration in an Ice-Ocean Model, J. Atmos. Oceanic Technol., 23, 742-749, doi:10.1175/JTECH1871.1, 2006.

Lisæter, K. A., Rosanova, J., and Evensen, G.: Assimilation of ice concentration in a coupled ice-ocean model, using the Ensemble Kalman filter, Ocean Dynam., 53, 368-388, doi:10.1007/s10236003-0049-4, 2003.

Marsland, S. J., Haak, H., Jungclaus, J. H., Latif, M., and Röske, F.: The Max-Planck-Institute global ocean/sea ice model with orthogonal curvilinear coordinates, Ocean Modell., 5, 91-127, 2003.
Maykut, G. A. and Untersteiner, N.: Some Results from a TimeDependent Thermodynamic Model of Sea Ice, J. Geophys. Res., 76, 1550-1575, 1971.

Mellor, G. L. and Kantha, L.: An ice-ocean Coupled Model, J. Geophys. Res., 94, 10937-10954, doi:10.1029/JC094iC08p10937, 1989.

Pohlmann, H., Jungclaus, J. H., Köhl, A., Stammer, D., and Marotzke, J.: Initializing Decadal Climate Predictions with the GECCO Oceanic Synthesis: Effects on the North Atlantic, J. Climate, 22, 3926-3938, doi:10.1175/2009JCLI2535.1, 2009.

Roeckner, E., Buml, G., Bonaventura, L., Brokopf, R., Esch, M., Giorgetta, M., Hagemann, S., Kirchner, I., Manzini, L. K. E., Rhodin, A., Schlese, U., Schulzweida, U., and Tompkins, A.: The atmospheric general circulation model ECHAM5, Tech. Rep. 349, Max Planck Institute for Meteorology, Hamburg, 2003.

Rothrock, D. A. and Wensnahan, M.: The accuracy of sea ice drafts measured from US Navy submarines, J. Atmos. Oceanic Technol., 24, 1936-1949, doi:10.1175/JTECH2097.1, 2007.

Saha, S., Moorthi, S., Pan, H. L., Wu, X. R., Wang, J. D., Nadiga, S., Tripp, P., Kistler, R., Woollen, J., Behringer, D., Liu, H. X., Stokes, D., Grumbine, R., Gayno, G., Wang, J., Hou, Y. T., Chuang, H. Y., Juang, H. M. H., Sela, J., Iredell, M., Treadon, R., Kleist, D., Van Delst, P., Keyser, D., Derber, J., Ek, M., Meng, J., Wei, H. L., Yang, R. Q., Lord, S., Van den Dool, H., Kumar, A., Wang, W. Q., Long, C., Chelliah, M., Xue, Y., Huang, B. Y., Schemm, J. K., Ebisuzaki, W., Lin, R., Xie, P. P., Chen, M. Y., Zhou, S. T., Higgins, W., Zou, C. Z., Liu, Q. H., Chen, Y., Han, Y., Cucurull, L., Reynolds, R. W., Rutledge, G., and Goldberg, M.: The NCEP Climate Forecast System Reanalysis, Bull. Amer. Meteor. Soc., 91, 1015-1057, doi:10.1175/2010BAMS3001.1, 2010.

Schweiger, A., Lindsay, R., Zhang, J. L., Steele, M., Stern, H., and Kwok, R.: Uncertainty in modeled Arctic Sea Ice volume, J. Geophys. Res., 116, C00D06, doi:10.1029/2011JC007084, 2011.

Semtner, A. J.: A Model for the Thermodynamic Growth of Sea Ice in Numerical Investigations of Climate, J. Phys. Oceanogr., 6, 379-389, 1976.

Serreze, M. C., Barrett, A. P., Slater, A. G., Steele, M., Zhang, J., and Trenberth, K. E.: The large-scale energy budget of the Arctic, J. Geophys. Res., 112, D11122, doi:10.1029/2006JD008230, 2007.

Shepherd, T. G., Arblaster, J. M., Bitz, C. M., Furevik, T., Goosse, H., Kattsov, V. M., Marshall, J., Ryabinin, V., and Walsh, J. E.: Report on WCRP Workshop on Seasonal to Multi-Decadal Predictability of Polar Climate (Bergen, Norway, 25-29 October 2010), SPARC Newsletter, 36, 11-19, http://www.atmosp. physics.utoronto.ca/SPARC/sparcnewsletter36.pdf, 2011.

Smith, D. M., Cusack, S., Andrew W, C., Folland, C. K., Harris, G. R., and Murphy, J. M.: Improved Surface Temperature Prediction for the Coming Decade from a Global Climate Model, Science, 317, 796-799, doi:10.1126/science.1139540, 2007.

Stark, J. D., Ridley, J., Martin, M., and Hines, A.: Sea Ice concentration and motion assimilation in a sea ice-ocean model, J. Geophys. Res., 113, C05S91, doi:10.1029/2007JC004224, 2008. 
Tonboe, R. and Nielsen, E.: Global Sea Ice Concentration Reprocessing Validation Report, Tech. rep., Danish Meteorological Institute, http://osisaf.met.no/p/ice/ice_conc_reprocessed. html, 2010.

Yi, D. and Zwally, J.: Arctic Sea Ice Freeboard and Thickness, http: //nsidc.org/data/nsidc-0393.html (last access: 11 January 2013), 2010.
Zhang, X. D.: Sensitivity of arctic summer Sea Ice coverage to global warming forcing: towards reducing uncertainty in arctic climate change projections, Tellus A, 62, 220-227, doi:10.1111/j.1600-0870.2010.00441.x, 2010. 